\section{SANDIA REPORT}

SAND99-1000

Unlimited Release

S. Printed May 1999
RESPVED

JUN 21 1999

OSTI

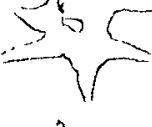

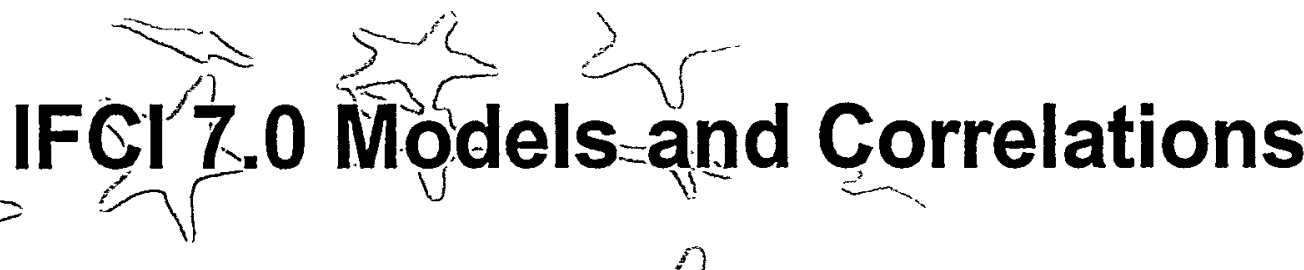<smiles>[Si]1[Si][Si][Si]1</smiles>
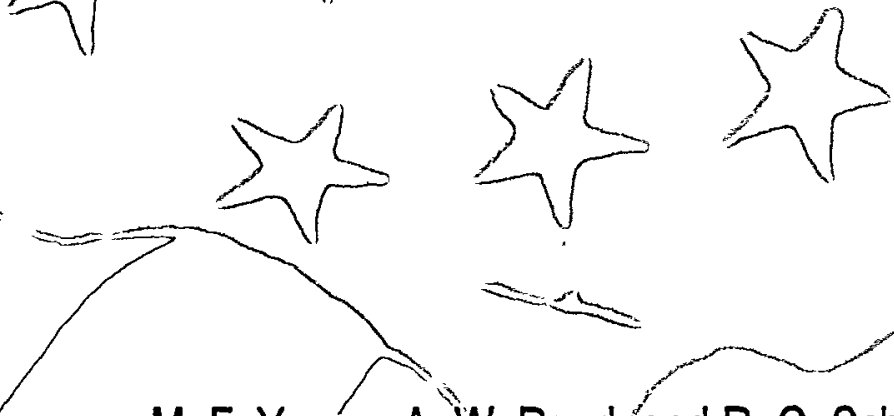

M. F. Young, A. W. Reed, and R. C. Schmidt

Prepared by

Sanália National Laboratories
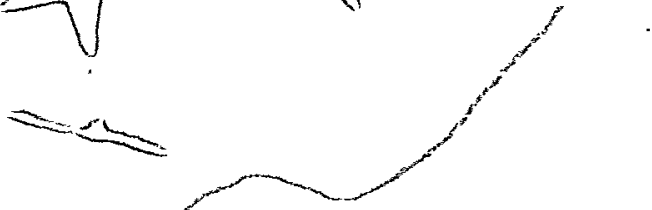

Sandia is a multiprogram laboratory operated by Sandia

Corporation, a Lockheed Martin Company, for the United States

Department of Energy under Contract DE-AC04-94AL85000.

Approved for public release; further dissemination unlimited. 
Issued by Sandia National Laboratories, operated for the United States Department of Energy by Sandia Corporation.

NOTICE: This report was prepared as an account of work sponsored by an agency of the United States Government. Neither the United States Government, nor any agency thereof, nor any of their employees, nor any of their contractors, subcontractors, or their employees, make any warranty, express or implied, or assume any legal liability or responsibility for the accuracy, completeness, or usefulness of any information, apparatus, product, or process disclosed, or represent that its use would not infringe privately owned rights. Reference herein to any specific commercial product, process, or service by trade name, trademark, manufacturer, or otherwise, does not necessarily constitute or imply its endorsement, recommendation, or favoring by the United States Government, any agency thereof, or any of their contractors or subcontractors. The views and opinions expressed herein do not necessarily state or reflect those of the United States Government, any agency thereof, or any of their contractors.

Printed in the United States of America. This report has been reproduced directly from the best available copy.

Available to DOE and DOE contractors from

Office of Scientific and Technical Information

P.O. Box 62

Oak Ridge, IN 37831

Prices available from (703) 605-6000

Web site: http://www.ntis.gov/ordering.htm

Available to the public from

National Technical Information Service

U.S. Department of Commerce

5285 Port Royal Rd

Springfield, VA 22161

NTIS price codes

Printed copy: A05

Microfiche copy: A01

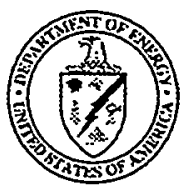




\section{DISCLAIMER}

Portions of this document may be illegible in electronic image products. Images are produced from the best available original document. 
SAND99-1000

Unlimited Release

Printed May 1999

\title{
IFCI 7.0 Models and Correlations
}

\author{
M. F. Young \\ Modeling and Analysis Department \\ A. W. Reed \\ YMP-Las Vegas Operations Department \\ R. C. Schmidt \\ Parallel Computational Science Department \\ Sandia National Laboratories \\ P.O. Box 5800 \\ Albuquerque, NM 87185-0739 \\ Report prepared for the \\ United States Nuclear Regulatory Commission \\ Office of Nuclear Regulatory Research
}

June 29, 1998

\begin{abstract}
The Integrated Fuel-Coolant Interaction Code (IFCI) is a best-estimate computer program for analysis of phenomena related to mixing of molten nuclear reactor core material with reactor coolant (water). The stand-alone version of the code, IFCI 7.0, has been designed for analysis of small- and intermediate-scale experiments in order to gain insight into the physics (including scaling effects) of molten fuel-coolant interactions. The code's methods, models, and correlations are being assessed. This report describes the flow regime, friction factor, and heattransfer models used in the current version of IFCI (IFCI 7.0).
\end{abstract}




\section{CONTENTS}

1. INTRODUCTION AND OVERVIEW ....................................................................................... 1

2. THREE-FIELD HYDRODYNAMIC FLUIDS MODEL ........................................................2

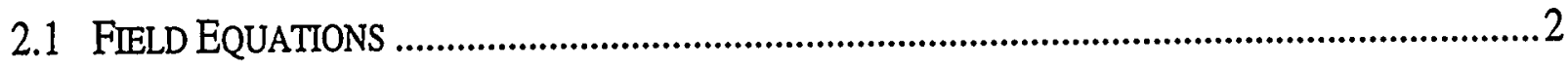

3. FLOW REGIME MODELS.............................................................................................5

4. INTERFIELD VISCOUS INTERACTION MODELS ...........................................................7

4.1 MELT-VAPOR/WATER INTERFACIAL FRICTION COEFFICIENTS ..............................................

4.1.1 Melt-Single Fluid Interfacial Drag Coefficient.......................................................... 8

4.1.2 Melt-Vapor/Liquid Interfacial Drag Coefficients ......................................................11

4.1.3 Melt-Water/Vapor Drag for Large Melt Diameter .................................................... 12

4.2 WATER-VAPOR INTERFACIAL FRICTION COEFFICIENTS ........................................................ 14

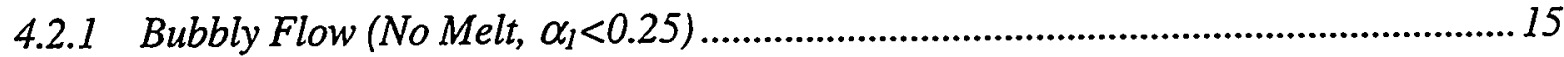

4.2.2 Bubbly Flow Adjusted for the Presence of Melt $(S>0.75)$........................................ 16

4.2.3 Mist Flow (No Melt, $\left.\alpha_{1}>0.75\right)$.................................................................................17

4.2.4 Mist Flow Adjusted for the Presence of Melt $(S<0.25)$............................................ 18

4.2.5 Interpolation Between Bubbly and Mist Flow..........................................................18

4.3 NUMERICAL IMPLEMENTATION ON THE STAGGERED GRID …..............................................19

5. INTERFIELD HEAT-TRANSFER MODELS .................................................................22

5.1 Heat TRansfer Between VAPor (Field 1) AND WATER (FIELD 2) ..................................2

5.1.1 Coefficients, Velocities, and Diameters ……...........................................................2

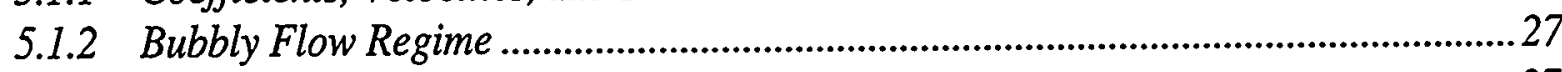

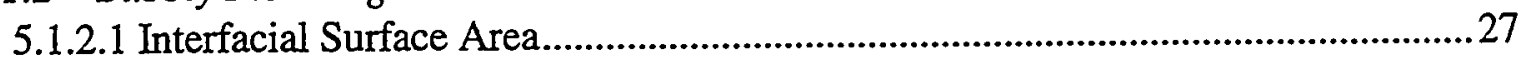

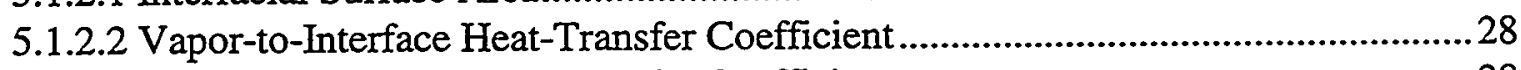

5.1.2.3 Interface-to-Water Heat-Transfer Coefficient ............................................................28

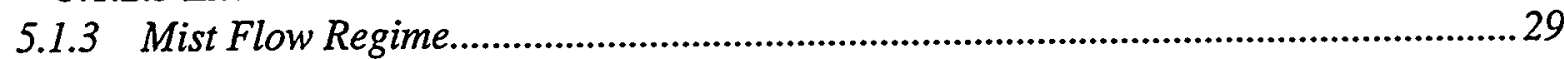

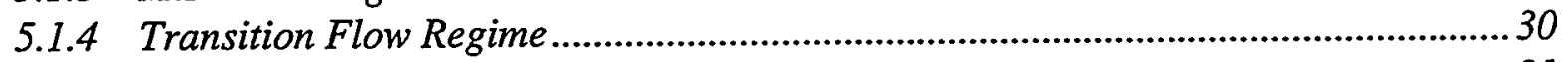

5.1.5 Review of Major Assumptions .................................................................................. 31

5.2 HEAT-TRANSFER BETWEEN MELT (FIELD 3) AND FIELDS 1 AND 2 (VAPOR AND WATER).. 32

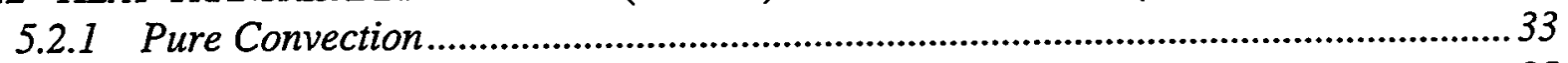

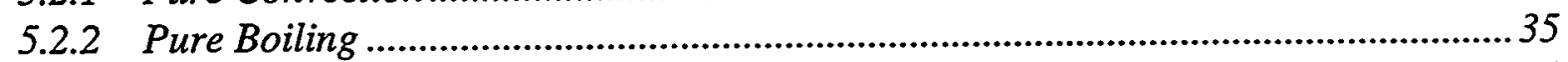

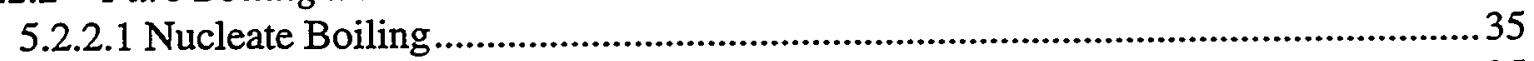

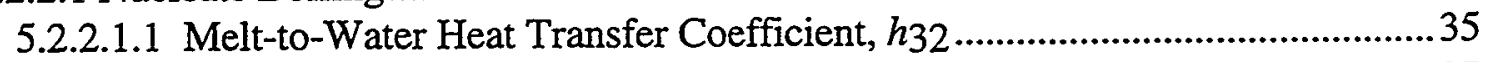

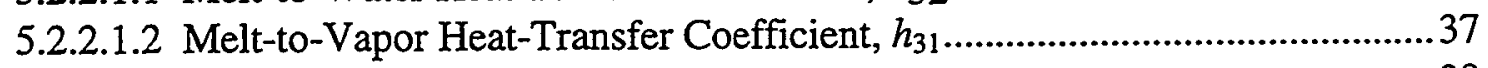

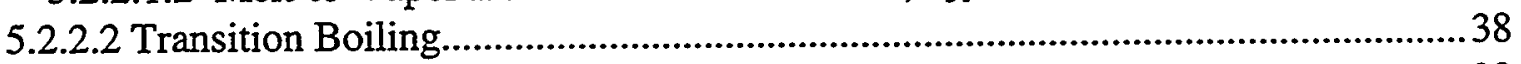

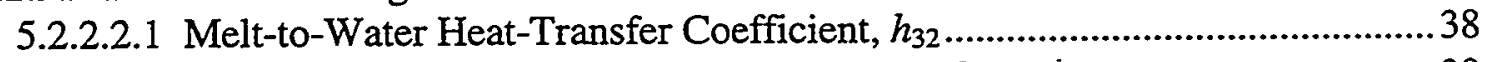

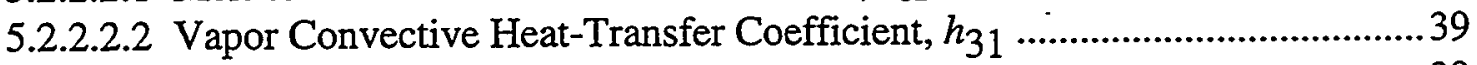

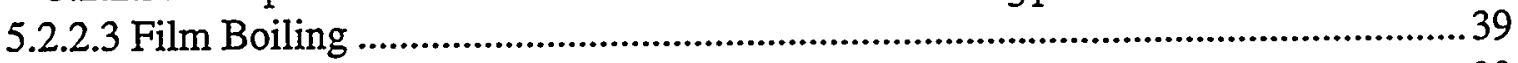

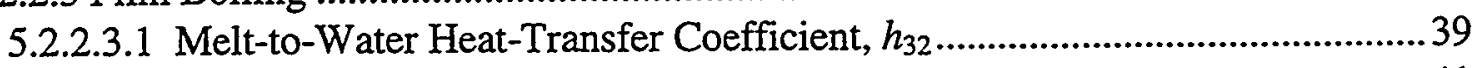

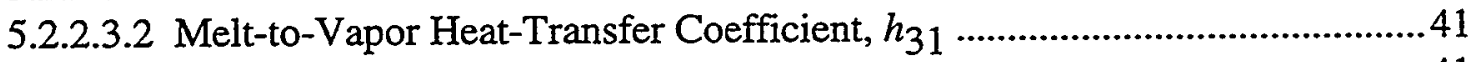

5.2.2.4 Critical Heat Flux .................................................................................................. 


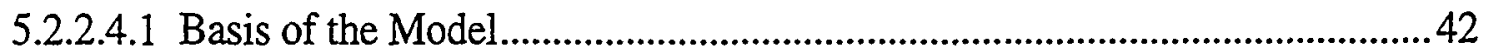

5.2.2.4.2 Assumptions and/or Approximations..........................................................43

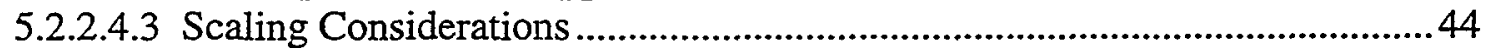

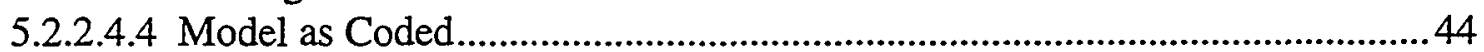

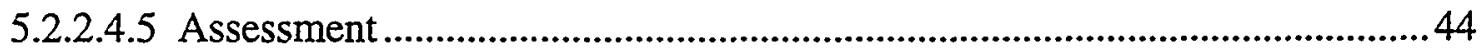

5.2.2.5 Minimum Stable Film-Boiling Temperature.......................................................45

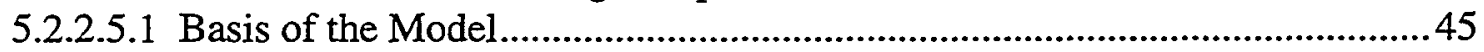

5.2.2.5.2 Assumptions and/or Approximations..............................................................46

5.2.2.5.3 Scaling Considerations ...............................................................................46

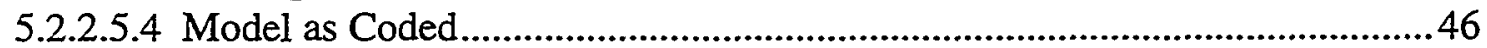

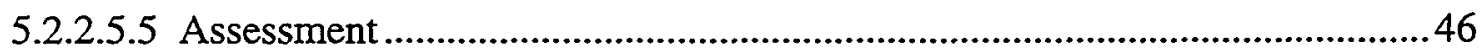

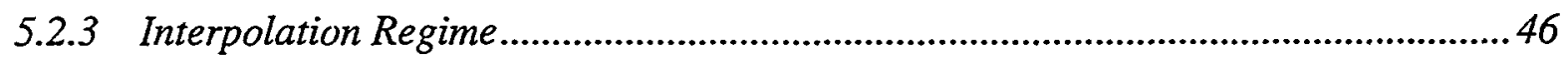

6. WATER-VAPOR PHASE CHANGE …..........................................................................48

7. MELT FRAGMENTATION AND SURFACE AREA TRANSPORT ............................49

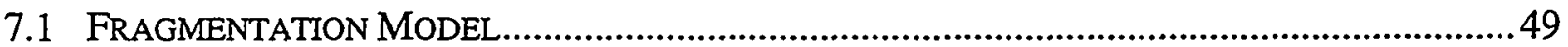

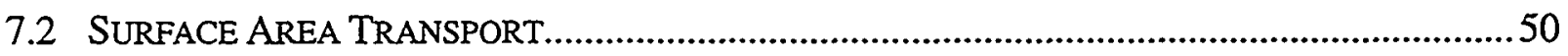

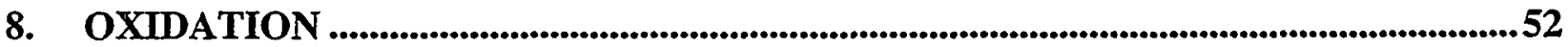

8.1 MELT OXIDATTON_HYDROGEN PRODUCTION MODEL ……….........................................53

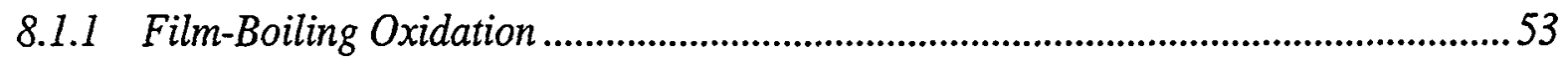

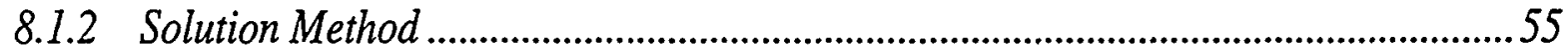

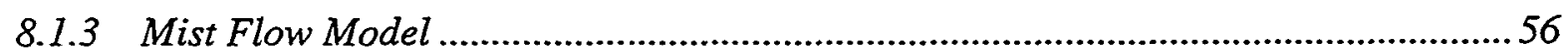

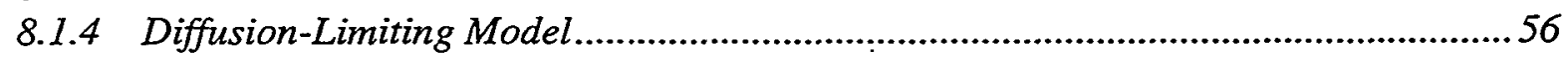

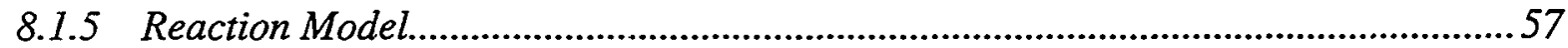

8.1.6 Metal Distribution in Melt................................................................................58

9. NUMERICAL SOLUTION OF FIELD EQUATIONS .................................................59

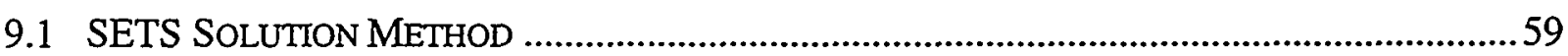

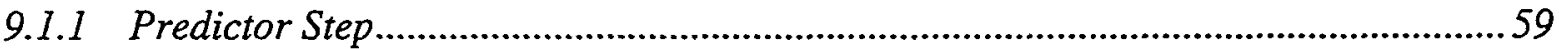

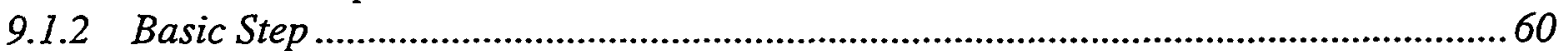

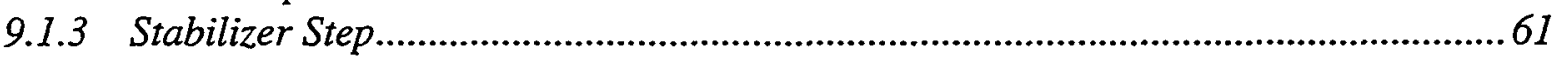

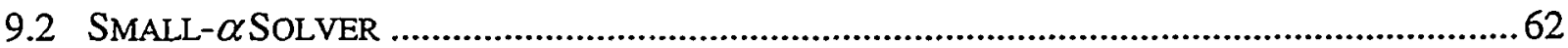

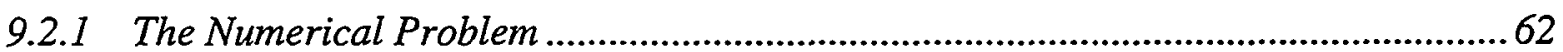

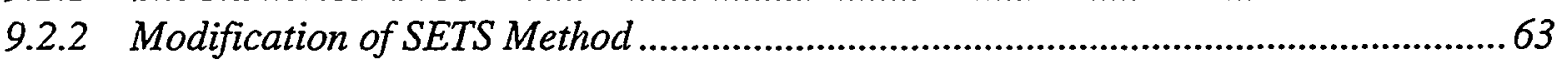

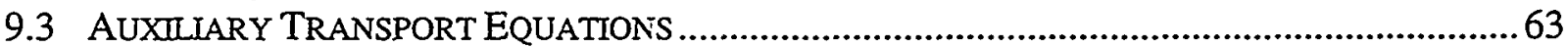

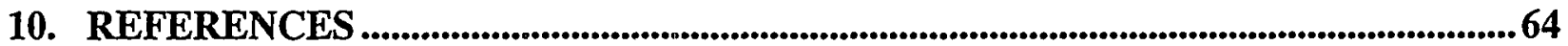




\section{Figures}

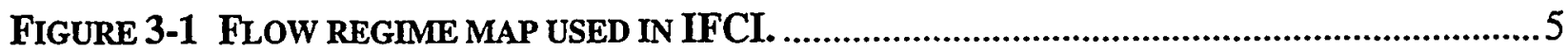

FIGURE 4-1 DRAG COEFFICIENT FOR A SINGLE PARTICLE. .......................................... 8

FIGURE 4-2 DRAG COEFFICIENT OF SPHERES BASED UPON THE ERGUN EQUATION (RECREATED

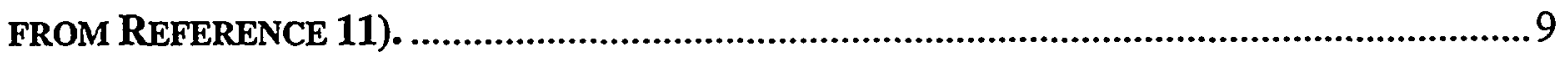

FIGURE 4-3 DRAG COEFFICIENT AS MODIFIED FOR IFCI.............................................. 10

FIGURE 4-4 LOCATION OF SOME KEY VARIABLES AS NEEDED IN THE FINITE-DIFFERENCE

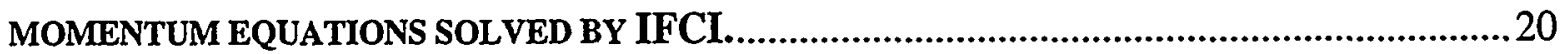

FIGURE 5-1 WATER AND VAPOR VELOCITIES AROUND A TYPICAL CONTROL VOLUME. ...........23

FIGURE 8-1 OXIDATION OF A SINGLE FUEL DROP IN WATER ...........................................52

\section{Tables}

TABLE 5.1. INTERFACIAL HEAT TRANSFER REGIONS FOR MELT (FIELD 3) IN THE PRESENCE OF

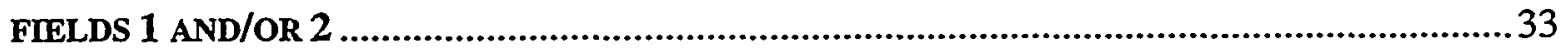




\begin{tabular}{|c|c|c|c|c|c|}
\hline \multicolumn{6}{|c|}{ Nomenclature } \\
\hline$a$ & interface acceleration & $\mathrm{m} / \mathrm{s}^{2}$ & $V_{r}$ & relative velocity & $\mathrm{m} / \mathrm{s}$ \\
\hline$A_{p}$ & projected area & $\mathrm{m}^{2}$ & $V_{s}$ & interstitial velocity & $\mathrm{m} / \mathrm{s}$ \\
\hline$c$ & concentration & $\mathrm{kmol} / \mathrm{m}^{3}$ & $W$ & axial speed & $\mathrm{m} / \mathrm{s}$ \\
\hline$C_{D}$ & drag coefficient & - & We & Weber number & - \\
\hline $\mathrm{CNB}$ & $\begin{array}{l}\text { number of bubbles in a } \\
\text { control volume }\end{array}$ & - & $\begin{array}{l}\Gamma \\
\alpha\end{array}$ & $\begin{array}{l}\text { mass production } \\
\text { volume fraction }\end{array}$ & $\mathrm{kg} / \mathrm{m}^{3}-\mathrm{s}$ \\
\hline $\begin{array}{l}C p \\
C_{R}\end{array}$ & $\begin{array}{l}\text { specific heat } \\
\text { interfacial friction }\end{array}$ & $\mathrm{J} / \mathrm{kg}-\mathrm{K}$ & $\alpha^{\prime}$ & normalized fluid volume & - \\
\hline$C_{Z}$ & $\begin{array}{l}\text { coefficient (radial) } \\
\text { interfacial friction }\end{array}$ & & $\beta$ & $\begin{array}{l}\text { fraction: } \alpha /\left(\alpha_{1}+\alpha_{2}\right) \\
\text { thermal expansion }\end{array}$ & $\mathrm{K}^{-1}$ \\
\hline$d$ & $\begin{array}{l}\text { coefficient (axial) } \\
\text { length }\end{array}$ & & $\varepsilon$ & $\begin{array}{l}\text { coefficient } \\
\text { fluid volume fraction }\end{array}$ & \\
\hline$D$ & diameter & $\begin{array}{l}\mathrm{m} \\
\mathrm{m}\end{array}$ & $\kappa$ & laminar relative & - \\
\hline$D_{A B}$ & $\begin{array}{l}\text { binary diffusion } \\
\text { coefficient }\end{array}$ & $\mathrm{m}^{2} / \mathrm{s}$ & $\rho$ & $\begin{array}{l}\text { permeability } \\
\text { density }\end{array}$ & $\mathrm{kg} / \mathrm{m}^{3}$ \\
\hline $\begin{array}{l}e \\
F\end{array}$ & internal energy & $\mathrm{J} / \mathrm{kg}$ & $\sigma$ & surface tension or & $\mathrm{N} / \mathrm{m}$ or \\
\hline $\begin{array}{l}F \\
f_{\text {vol }}\end{array}$ & force & $\mathrm{N}_{2}$ & & Boltzman's constant & \\
\hline$f_{\text {vol }}$ & $\begin{array}{l}\text { flow volume } \\
\text { mass flux }\end{array}$ & $\begin{array}{l}\mathrm{m}^{3} \\
\mathrm{~kg} / \mathrm{m}^{2}-\mathrm{s}\end{array}$ & & Subscripts & \\
\hline $\begin{array}{l}\mathrm{Gr} \\
h\end{array}$ & Grashof number & - & 1 & water liquid & \\
\hline $\begin{array}{l}h \\
K\end{array}$ & heat transfer coefficient & $\mathrm{W} / \mathrm{m}^{2}-\mathrm{K}$ & 2 & water vapor/hydrogen & \\
\hline$K$ & $\begin{array}{l}\text { "turbulent" relative } \\
\text { permeability }\end{array}$ & - & $\begin{array}{l}3 \\
b\end{array}$ & $\begin{array}{l}\text { melt } \\
\text { bubble }\end{array}$ & \\
\hline $\begin{array}{l}k \\
k_{x}\end{array}$ & thermal conductivity & $\mathrm{W} / \mathrm{m}-\mathrm{K}$ & $\mathrm{CHF}$ & critical heat flux & \\
\hline $\begin{array}{l}k_{x} \\
L\end{array}$ & mass transfer coefficient & $\mathrm{kmol} / \mathrm{m}^{2}-\mathrm{s}$ & crit & critical point & \\
\hline$L$ & $\begin{array}{l}\text { length or } \\
\text { enthalpy of vaporization }\end{array}$ & $\underset{\mathrm{J}}{\mathrm{m}}$ & $\begin{array}{l}\text { film } \\
\text { force }\end{array}$ & $\begin{array}{l}\text { film boiling } \\
\text { forced convection }\end{array}$ & \\
\hline $\begin{array}{l}M \\
N\end{array}$ & interfacial drag force & $\mathrm{N} / \mathrm{m}^{3}$ & free & free convection & \\
\hline $\begin{array}{l}N \\
\mathrm{Nu}\end{array}$ & number of drops & - & i & liquid/vapor interface & \\
\hline $\begin{array}{l}\mathrm{Nu} \\
P\end{array}$ & Nusselt number & - & $\max$ & maximum & \\
\hline $\begin{array}{l}P \\
\operatorname{Pr}\end{array}$ & pressure & $\mathrm{Pa}$ & $\min$ & minimum & \\
\hline $\begin{array}{l}\operatorname{Pr} \\
Q\end{array}$ & Prandtl number & $-\quad 3$ & $R$ & radial direction & \\
\hline$Q$ & $\begin{array}{l}\text { specific energy } \\
\text { generation }\end{array}$ & $\mathrm{W} / \mathrm{m}^{3}$ & $\begin{array}{l}r \\
\mathrm{rad}\end{array}$ & $\begin{array}{l}\text { relative } \\
\text { radiation }\end{array}$ & \\
\hline $\begin{array}{l}q \\
\operatorname{Re}\end{array}$ & heat flux & $\mathrm{W} / \mathrm{m}^{2}$ & $s$ & interstitial & \\
\hline $\begin{array}{l}\operatorname{Re} \\
S\end{array}$ & Reynolds number & - & sat & saturation condition & \\
\hline $\begin{array}{l}S \\
\text { SA }\end{array}$ & saturation & - & term & terminal & \\
\hline $\begin{array}{l}\text { SA } \\
\text { Sc }\end{array}$ & structure surface area & $\mathrm{m}^{2}$ & $x$ & vapor/liquid mixture & \\
\hline $\begin{array}{l}\mathrm{Sc} \\
t\end{array}$ & Schmidt number & - & $Z$ & axial direction & \\
\hline $\begin{array}{l}t \\
U\end{array}$ & $\begin{array}{l}\text { time } \\
\text { radial sneed }\end{array}$ & $\mathrm{s}$ & & & \\
\hline$u$ & $\begin{array}{l}\text { radial speed } \\
\text { absolute viscosity }\end{array}$ & & - & $\begin{array}{l}\text { Superscripts } \\
\text { average }\end{array}$ & \\
\hline$V$ & $\begin{array}{l}\text { absolute viscosity } \\
\text { velocity }\end{array}$ & $\begin{array}{l}\mathrm{N}-\mathrm{s} / \mathrm{m}^{2} \\
\mathrm{~m} / \mathrm{s}\end{array}$ & & & \\
\hline vol & volume & & & & \\
\hline
\end{tabular}




\section{INTRODUCTION AND OVERVIEW}

The Integrated Fuel-Coolant Interaction (IFCI) code is a three-field compressible hydrodynamic code designed to model the mixing of molten nuclear reactor materials with reactor coolant (water). It is designed to handle, with varying degrees of empiricism, the four stages of fuelcoolant interactions: coarse mixing, triggering, detonation propagation, and hydrodynamic expansion. IFCI is under development at Sandia National Laboratories (SNL), and is sponsored by the U.S. Nuclear Regulatory Commission, Office of Nuclear Regulatory Research (USNRC/RES).

IFCI contains models for boiling rates, flow regimes, dynamic melt fragmentation, surface tracking, subcooling effects, melt oxidation, triggering, and propagation of the shock. These phenomena are essential to the modeling of fuel-coolant interactions (FCIs). Relatively brief descriptions of many of these models have been provided in earlier reports [1,2]. In addition, a fairly detailed description of the models for melt fragmentation and droplet breakup is given in Reference [3]. The purpose of this report is to provide a detailed description of the flow regime, friction factor, and heat transfer models that are used in IFCI 7.0. A description is also given of the field equations solved and the numerical solution algorithm.

The description of the constitutive relations (flow regime, friction factor, and heat-transfer relations) in this report applies to both IFCl 6.2 and IFCI 7.0. The field equation description is the same except for the momentum equations, which are nonconservative in IFCI 6.2. The numerical solution technique is also almost the same in the two codes, except for the solution of the momentum equations, which in IFCI 6.2 follows the (SETS) method without correction of the momentum equations for numerical diffusion.

Section 2 provides a synopsis of the hydrodynamic fluids model and the governing conservation equations that provide that framework for all of the IFCI models. Section 3 describes the flow regime maps that are used in IFCI. These are three-field maps in IFCI 6.2 and IFCI 7.0, as opposed to the two-field maps used in earlier versions of IFCI, which were adopted primarily from TRAC [4,5] and MELPROG [6,7]. In Section 4 the friction factor modeling is described. In Section 5, interfield heat-transfer models are described in detail. These include the heat transfer between vapor and water (Section 5.1), and between melt and the vapor and water (Section 5.2). Section 6 describes the phase-change (boiling) models in IFCI. Section 7 describes the melt fragmentation model and surface area transport. Section 8 describes the melt oxidation model, and Section 9 describes the numerical solution technique. 


\section{THREE-FIELD HYDRODYNAMIC FLUIDS MODEL.}

The IFCI hydrodynamic fluids model was developed from the two-dimensional, four-field hydrodynamics model implemented in MELPROG [6,7] and uses hydrodynamics subroutines from the MELPROG FLUIDS module extensively. Furthermore, IFCI drivers and input and output routines were derived from MELPROG subroutines. The MELPROG hydrodynamics model was designed to treat up to four fields: (1) vapor (steam and $\mathrm{H}_{2}$ ), (2) water, (3) debris, and (4) melt (in MELPROG, these are referred to as fields 1,2,3, and 4 respectively). Therefore, it is usually referred to as a four-field hydrodynamics model. In practice, however, MELPROG's fluid fields for solid debris (field 3) and melt (field 4) were not coupled because the modeling information needed to separate fields 3 and 4 was deemed inadequate, and all corium, regardless of solid-liquid state, was placed in field 3, leaving the fourth field inactive. In other words, MELPROG was always run with the fields for vapor, water, and debris "on," and the melt field was "off." In contrast, IFCI is always run with the steam, water, and melt fields "on," and the debris field is "off." As MELPROG did with field 3, all corium treated by IFCI, regardless of solid-liquid state, is placed in field 3, but the interfield coupling terms with field 3 are uniquely IFCI models, not MELPROG models. Therefore, strictly speaking, IFCI uses a three-field hydrodynamics model, even though previous documentation has often referred to the model as a four-field model (with one field inactive).

\subsection{Field Equations}

The equation set used in IFCl is a three-field, two-dimensional, cylindrical geometry version of a set commonly used in multifield computational hydrodynamics and originally derived from the general field equations of Ishii [8,9]. A "field" in the context of multifield hydrodynamics is represented by separate momentum, mass continuity, and energy equations for each type and phase of material. These three equations are solved for each "field." Mass, energy, and momentum transfer between fields are represented by coupling terms in the field equations for which constitutive relations must be provided. Also necessary is an equation of state for each field. Use of a multifield method with separate mass, momentum, and energy equations for each field allows slip between the various materials (vapor, coolant, and melt), and a different temperature for each material. The field equations, associated constitutive relations, equations of state, and initial and boundary conditions, are solved in IFCI by use of a variation of the SETS method developed by Mahaffy [10].

The basic conservation equations used in IFCI for each field $k$ are given below in Eqs. (2.1) through (2.4). Values of $k$ equal to 1, 2, and 3 denote the vapor, water, and melt fields respectively. Whenever a summation is used to indicate various interfield terms, the subscript $j$ is also used to refer to the different fields, and the sum is over $j$ for $j \neq k$. 
Mass conservation:

$0=\frac{\partial}{\partial t}\left(\alpha_{k} \rho_{k}\right)+\nabla \cdot\left(\alpha_{k} \rho_{k} \vec{V}_{k}\right)-\sum_{j=1}^{3} \Gamma_{j k}-\Gamma_{k}$

Axial momentum:

$$
\begin{aligned}
0 & =\frac{\partial}{\partial t}(\alpha \rho W)_{k}+\nabla \cdot(\alpha \rho \vec{V} \bar{V})_{k}+\alpha_{k} \frac{\partial P}{\partial z}+\sum_{j=1}^{3} C_{Z j k}\left(W_{k}-W_{j}\right)\left|W_{k}-W_{j}\right| \\
& +D Z_{k} W_{k}\left|W_{k}\right|+(\alpha \rho)_{k} g
\end{aligned}
$$

Radial momentum:

$$
\begin{aligned}
0 & =\frac{\partial}{\partial t}(\alpha \rho U)_{k}+\nabla \cdot(\alpha \rho \bar{V} \bar{V})_{k}+\alpha_{k} \frac{\partial P}{\partial r}+\sum_{j=1}^{3} C_{R j k}\left(U_{k}-U_{j}\right)\left|U_{k}-U_{j}\right| \\
& +D R_{k} U_{k}\left|U_{k}\right|
\end{aligned}
$$

Energy:

$$
\begin{aligned}
0= & \frac{\partial}{\partial t}\left(\alpha_{k} \rho_{k} e_{k}\right)+\nabla \bullet\left(\alpha_{k} \rho_{k} e_{k} \vec{V}_{k}\right)+P\left[\frac{\partial \alpha_{k}}{\partial t}+\nabla \bullet \alpha_{k} \vec{V}_{k}\right] \\
& -\sum_{j=1}^{3} \Gamma_{j k} \mathrm{H}_{s k}-\sum_{j=1}^{3} Q_{j k}-Q_{w k}-Q_{s k}
\end{aligned}
$$

In addition, a constraint on the sum of the fluid volume fractions is also required. By definition these volume fractions must always add to one, thereby satisfying the following equation:

$$
1-\alpha_{s}-\sum_{k=1}^{3} \alpha_{k}=0
$$

In Eqs. (2.1) through (2.5), $\alpha_{k}$ is the volume fraction with respect to the total finite-differencemesh cell volume. There can also be a nonflow volume fraction in the cell, as structures $\alpha_{s}$. The velocity vector, $\vec{V}_{k}$, is composed of axial and radial components $W_{k}$ and $U_{k}$. The third and fourth terms in Eq. (2.1) represent mass transfer among the fields and external mass source terms, respectively. The mass transfer between steam and liquid water is treated implicitly in temperature and pressure, while the other mass transfers are explicit sources. In the momentum 
equations, the fourth term represents momentum transfer between the fields, and the fifth term represents wall friction. The interfacial fraction coefficients, $C_{2 j k}$ and $C_{R j k}$, are evaluated explicitly based on the local flow regime. In the energy equation [see Eq. (2.4)], the third term is the work term. The fourth term represents energy exchange between the fields due to phase change, with $H_{s k}$ representing the saturation enthalpy. The fifth term represents heat transfer between fields. The sixth term represents external energy sources, and the seventh term is energy transfer to an interface at saturation.

Because there are three fields being treated, Eqs. (2.1) through (2.5) constitute a set of thirteen coupled, nonlinear, partial differential equations that, along with material equations of state and constitutive relations for mass, energy, and momentum exchange, form the hydrodynamic equation set of IFCI. 


\section{FLOW REGIME MODELS}

There is currently a dearth of information about flow regime maps for three-component flows. Most of the information available is for two-phase flows of immiscible fluids, two-phase flows in packed beds, and for fluidized beds in which there is a single fluid. There does not appear to be a complete flow regime map for three-component flows.

Three conventional flow regime descriptions are used in IFCI: (1) bubbly flow, (2) mist flow, and (3) flow in packed beds (Figure 3-1). Bubbly flow occurs in gas-liquid systems when the liquid is the continuous phase and the gas is the discontinuous phase. The constraint for bubbly flow is typically a critical gas volume fraction. In IFCI, the critical vapor volume fraction for bubbly flow is set to 0.25 .

Mist flow occurs in gas-liquid systems when the vapor is the continuous phase and the liquid is the discontinuous phase. The constraint for droplet flow is typically a critical liquid volume fraction. In IFCI, the critical liquid volume fraction for mist flow is set to 0.25 . Flow regimes for two-phase flow between bubbly and mist are defined only for pipe flows and are not applicable to IFCI.

Packed beds are composed of solid particulate which are in contact with each other. Both singlephase and two-phase flows through packed beds are reasonably well characterized. Solidvolume fractions for packed beds are typically greater than $60 \mathrm{vol} \%$.

When the upward flow of a fluid through a packed bed is sufficiently large, the particles lose contact with each other and become suspended in the flow. When this occurs, the bed is said to be fluidized. Solid-volume fractions for fluidized beds can drop to about $50 \mathrm{vol} \%$. The equations for single-phase flow in packed beds are also used to describe flow in fluidized beds. Two-phase flows in fluidized beds are not well characterized.

The melt component has the largest surface tension of the three constituents of interest. During coarse mixing, it is anticipated that neither water nor vapor will exist as a discontinuous phase within the melt. For this reason, the packed bed correlations are deemed to be the most applicable for water and vapor flows through dense arrays of melt drops. 
The regions that are not shaded in Figure 3-1 are described by conventional flow regimes. Because of the absence of data, these regions are modeled by interpolating between the known regions (bubbly, mist, packed bed). The only constraint on the interpolating function is continuity. For simplicity, the interpolating functions are linear. 


\section{INTERFIELD VISCOUS INTERACTION MODELS}

The fourth term in both Eqs. (2.2) and (2.3) accounts for the change of momentum due to viscous interactions with other fluid fields. These terms have been represented using the interfacial friction coefficients $C_{Z j k}$ and $C_{R j k}$. For the current IFCI configuration of three active fields, this requires the specification of up to six different coefficients at a given location: $C_{Z 12}, C_{Z 13}, C_{Z 23}$, $C_{R 12}, C_{R 13}$, and $C_{R 23}$. Note that the coefficient matrix is symmetric so that, for example, $C_{Z 12}=$ $C_{Z 21}$.

In IFCI, a simple flow regime map is utilized to provide a means of characterizing the multiphase flow. This flow map is the basis for interfacial viscous interactions as well as heat transfer, and has been described in Section 3. The correlations used for calculating the melt interfacial friction coefficients with the water and the vapor are described first in Section 4.1. The correlations for vapor water friction coefficients are described in Section 4.2. The numerical implementation of the interfacial friction coefficients is described in Section 4.3.

\subsection{Melt-Vapor/Water Interfacial Friction Coefficients}

The interfacial friction coefficients between the melt and the other two phases (water and vapor) are calculated using two methods that depend on whether the effective diameter of the melt is less than or greater than the cell size. If the melt diameter is less than the cell size, friction coefficients are calculated using the flow map described in Section 3. If the melt diameter is greater than the cell size, friction coefficients are calculated assuming a flat, but "wavy," meltwater/vapor surface with the water or vapor treated as a composite phase. The basic assumptions inherent in the formulation of the melt-vapor/water interfacial friction coefficients are as follows:

1. The interfacial drag between melt and the water/vapor mixture can be approximated by treating the melt as rigid spheres.

2. The effective melt diameter is an initial value defined by the user of the code in the input; it may be reduced by the fragmentation or detonation models.

3. The transient is sufficiently slow that interfacial drag phenomena are quasi-steady.

The interfacial drag force (in $\mathrm{N} / \mathrm{m}^{3}$ ) on the melt by fluid $i$ is

$$
M_{3, i}=\frac{\alpha_{3} F_{3, i}}{\operatorname{vol}_{3}}
$$

where

$$
\begin{array}{ll}
\alpha_{3} & =\text { melt phase volume fraction, } \\
F_{3, i} & =\text { the drag force on a single melt droplet from fluid } i(\mathrm{~N}) \\
\operatorname{vol}_{3} & =\text { the volume of a single melt droplet, } \operatorname{vol}_{3}=\frac{1}{6} \pi\left(D_{3}\right)^{3}, \text { and } \\
i & =1 \text { for vapor, } 2 \text { for liquid. }
\end{array}
$$


Because this relation assumes steady-state conditions, the force on the droplet is caused by skin friction and form drag only. The drag force is approximated in terms of a standard steady-state drag coefficient as

$$
F_{3, i}=\frac{1}{2} C_{D 3, i} \rho_{i} V_{r 3, i}\left|V_{r 3, i}\right| A_{P 3}
$$

where

$$
\begin{aligned}
& C_{D 3, i}=\text { melt drag coefficient for fluid } i \\
& \rho_{i}=\text { density of fluid } i \\
& V_{r 3, i}=\text { relative velocity between the melt and fluid } i,\left|V_{i}-V_{3}\right|, \text { and } \\
& A_{P 3}=\text { projected area of the melt droplet, } A_{P 3}=\frac{1}{4} \pi D_{3}^{2} .
\end{aligned}
$$

Combining Eqs. (4.1) and (4.2), we can write

$$
M_{3, i}=\frac{1}{2} \alpha_{3} C_{D 3, i} \rho_{i} V_{r 3, i}\left|V_{r 3, i}\right| \frac{A_{P 3}}{\operatorname{vol}_{3}}
$$

Use of the relations for projected area and volume of a droplet in Eq. (4.3) yields

$$
M_{3, i}=\frac{3}{4} \frac{\alpha_{3}}{D_{3}} C_{D 3, i} \rho_{i} V_{r 3, i}\left|V_{r 3, i}\right|
$$

\subsubsection{Melt-Single Fluid Interfacial Drag Coefficient}

When the volume fraction of melt is sufficiently small, the boundary layers on the outside of a melt particle do not interact. Under this condition, the drag coefficients for a single particle are applicable. The drag coefficient for a single rigid particle is shown in Figure 4-1 as a function of the Reynolds number. In the region where Stokes flow is valid $(\operatorname{Re}<2)$, the drag coefficient is inversely proportional to the Reynolds number [11]. For Reynolds numbers between 500 and 50,000 (the Newtonian region, where boundary-layer separation occurs at midpoint of the particle), the drag coefficient is constant [11]. The region

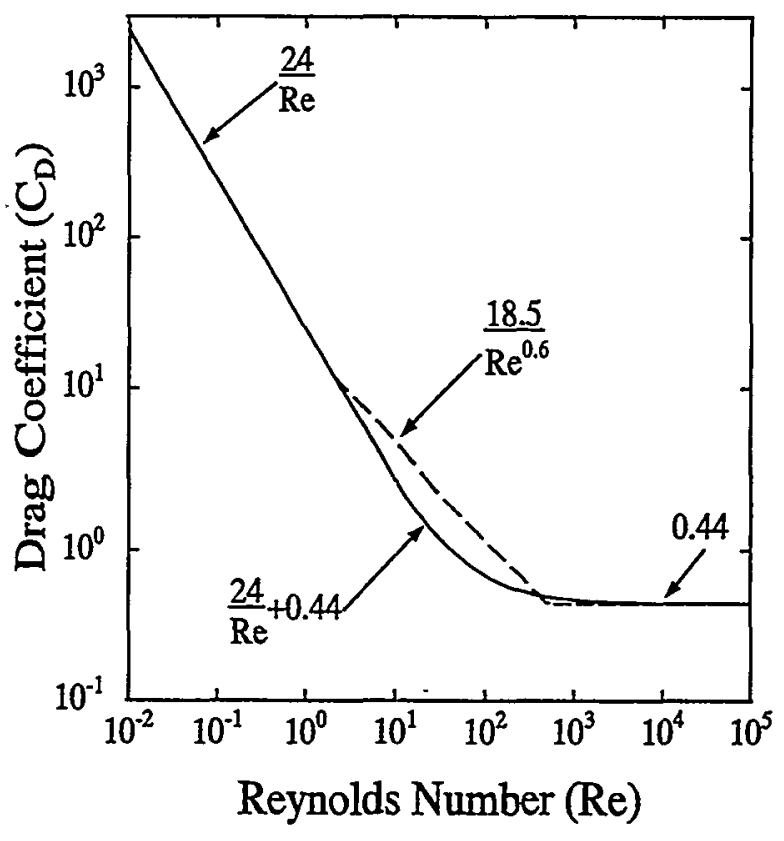

Figure 4-1 Drag coefficient for a single particle. 
between 2 and 500 does not have a good closed-form solution. Interpolating functions based upon empirical data are typically used for this region. One commonly used function is shown in Figure 4-1 as a dashed line [11].

As will be seen in the following section, commonly used fits for the transition region are inconvenient when modified for three-phase flow. For that reason, the single-particle drag coefficient is modeled as the linear sum of the Stokes component and the Newtonian component. This produces a single smooth function without deviating significantly from conventional correlations:

$$
C_{D, \text { single }}=\frac{24}{\operatorname{Re}}+0.44
$$

For high-volume fractions of melt, the drag coefficient is based upon the Ergun equation for packed beds [11]. The Ergun equation accommodates both the laminar and the "turbulent" regions of flow in packed beds, and is posed in terms of the mass flux $\left(G, \mathrm{~kg} / \mathrm{m}^{2}-\mathrm{s}\right)$, the fluid volume fraction $(\varepsilon)$, and the particle diameter $(D)$.

$$
\frac{\Delta P}{L}=150 \frac{(1-\varepsilon)^{2}}{\varepsilon^{3}} \frac{\mu_{f}}{\rho_{f} D^{2}} G+1.75 \frac{(1-\varepsilon)}{\varepsilon^{3}} \frac{1}{\rho_{f} D} G^{2}
$$

The drag coefficient extracted from the Ergun equation is given by the equation

$$
C_{D, \text { Ergun }}=\frac{200}{\operatorname{Re}} \frac{1-\varepsilon}{\varepsilon^{2}}+\frac{7}{3 \varepsilon}
$$

where the Reynolds number is based upon the interstitial velocity $\left(V_{s}\right)$.

$$
V_{s}=\frac{G}{\rho_{f} \varepsilon}
$$

The Ergun-based drag coefficient [Eq. (4.7)] is compared with the single-particle drag coefficient [Eq. (4.5)] in Figure 4-2. The Ergun equation is seen to match the singleparticle drag coefficient in the laminar Stokes flow region for a fluid-volume fraction of 0.917. This corresponds to an interparticle spacing of about two diameters.

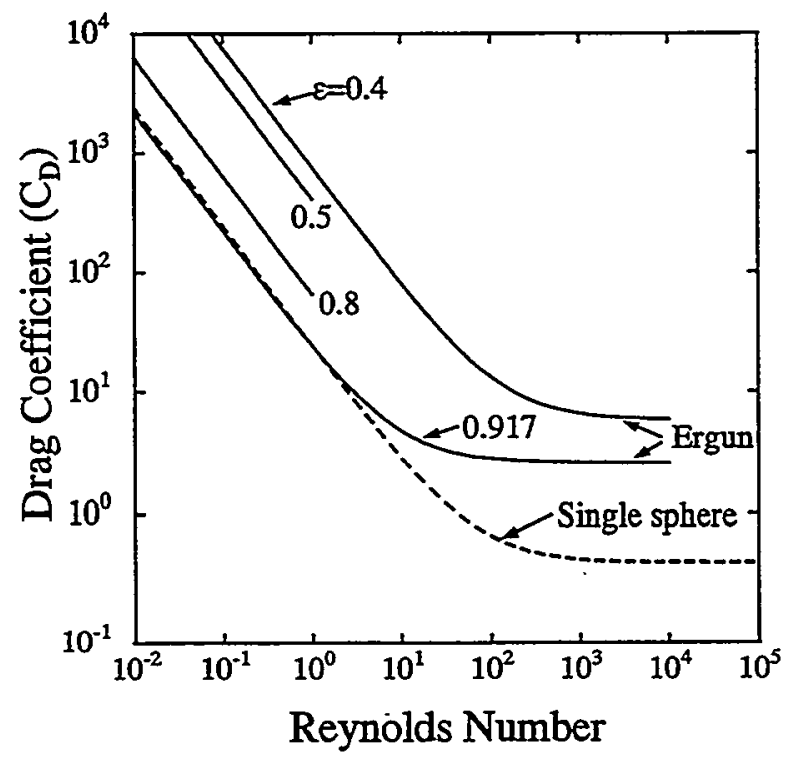

Figure 4-2 Drag coefficient of spheres based upon the Ergun equation (recreated from Reference 11). 
In the Newtonian flow region, the Ergun equation produces a minimum drag coefficient of $7 / 3$, while a value of 0.44 is normal for a single particle. While it is common to use the Ergun equation in fluidized beds where the fluid-volume fraction can reach to about 0.5 , there is no basis for replacing the single-particle asymptotic limit of 0.44 by the value of $7 / 3$. Therefore, it was decided to interpolate between these two values. The final form for the single-fluid melt drag coefficient in IFCI is

$$
C_{D}=\frac{200}{\operatorname{Re}} \max \left[\begin{array}{c}
\left(\frac{1-\varepsilon}{\varepsilon^{2}}\right) \\
\left(\frac{1-0.917}{0.917^{2}}\right)
\end{array}\right]+\left\{\frac{7}{3} \min \left[\begin{array}{c}
\left(\frac{1-\varepsilon}{0.6}\right) \\
1
\end{array}\right]+0.44 \max \left[\begin{array}{c}
\left.\left(\frac{\varepsilon-0.4}{0.6}\right)\right] \\
0
\end{array}\right]\right\} \frac{1}{\varepsilon}
$$

A plot of this function is shown for various fluid-volume fractions in Figure 4-3. This function collapses to the Ergun equation at a fluid fraction of 0.4 and to the single-particle equation at a fluid fraction of 1.0.

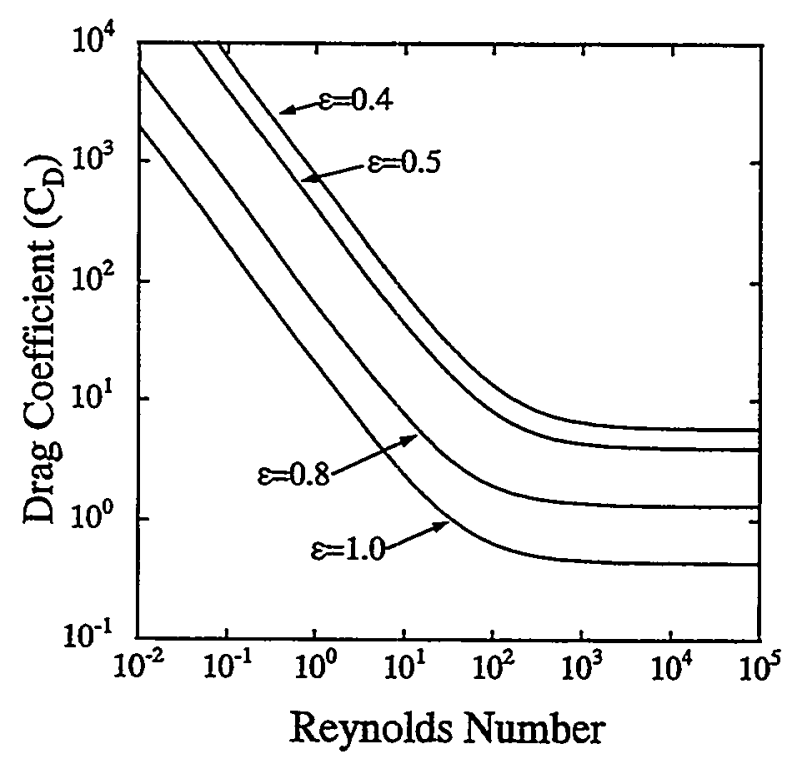

Figure 4-3 Drag coefficient as modified for IIFCI. 


\subsubsection{Melt-Vapor/Liquid Interfacial Drag Coefficients}

In packed beds, the Ergun equation is extended to two-fluid flows through the use of "relative permeabilitiès" $[12,13]$. The laminar and turbulent relative permeabilities $(\kappa, K)$ adjust the flow equations for the presence of a second immiscible fluid. These terms account for the volume fraction of each component as well as the size of the pore occupied by each fluid.

$$
\begin{aligned}
& \frac{\Delta P}{L}=150 \frac{(1-\varepsilon)^{2}}{\varepsilon^{3}} \frac{\mu_{1}}{\rho_{1} D^{2} K_{1}} G_{1}+1.75 \frac{(1-\varepsilon)}{\varepsilon^{3}} \frac{1}{\rho_{1} D K_{1}} G_{1}{ }^{2} \\
& \frac{\Delta P}{L}=150 \frac{(1-\varepsilon)^{2}}{\varepsilon^{3}} \frac{\mu_{2}}{\rho_{2} D^{2} K_{2}} G_{2}+1.75 \frac{(1-\varepsilon)}{\varepsilon^{3}} \frac{1}{\rho_{2} D K_{2}} G_{2}{ }^{2}
\end{aligned}
$$

Drag coefficients are derived from these extended Ergun equations in a manner similar to that for the single-fluid case.

$$
\begin{aligned}
& C_{D, \text { Ergun, },-3}=\frac{200}{\operatorname{Re}} \frac{1-\varepsilon}{\varepsilon^{2}} \frac{(1-S)^{2}}{\kappa_{1}}+\frac{7}{3 \varepsilon} \frac{(1-S)^{3}}{K_{1}} \\
& C_{D, \text { Ergun, } 2-3}=\frac{200}{\operatorname{Re}} \frac{1-\varepsilon}{\varepsilon^{2}} \frac{S^{2}}{\kappa_{2}}+\frac{7}{3 \varepsilon} \frac{S^{3}}{K_{2}} \\
& \text { where } S=\frac{\alpha_{2}}{\alpha_{1}+\alpha_{2}} \varepsilon=\alpha_{1}+\alpha_{2}
\end{aligned}
$$

An upper bound for the relative permeabilities is obtained by ignoring the effects of surface tension and accounting only for the nominal saturation ( $S$, the fraction of nonsolid volume occupied by the wetting fluid). Under this assumption, the liquid and the vapor are modeled as if they occupied separate particle beds. For this case, the relative permeabilities are calculated to be

$$
\begin{array}{ll}
\kappa_{1}=(1-S) & K_{1}=(1-S)^{2} \\
\kappa_{2}=S \quad K_{2}=S^{2} \\
\text { where } S=\frac{\alpha_{2}}{\alpha_{1}+\alpha_{2}}
\end{array}
$$

Relative permeabilities in packed beds with small particles are actually smaller than those given by Eq. (4.12) $[13,14,15]$. The wetting liquid occupies smaller pores that have a higher specific solid surface area, thus producing more drag on the liquid. In addition, both the liquid and the vapor must intertwine, producing path lengths for each that are longer than if the fluids were in separate beds. 
The choice of relative permeabilities is guided by the fact that the flow regime of principal interest involves melt volume fractions lower than 0.5. This is outside the proven range of relative permeability correlations. So far, no database on drag has been identified for this flow regime. Furthermore, the melt is expected to be above the Leidenfrost temperature for most cases of interest. This means that the water will not wet the melt. For these reasons, relative permeabilities based only on volume fraction [Eq. (4.12)] are chosen. When Eq. (4.11) is modified to look like Eq. (4.9), and the relative permeabilities are substituted, the result is

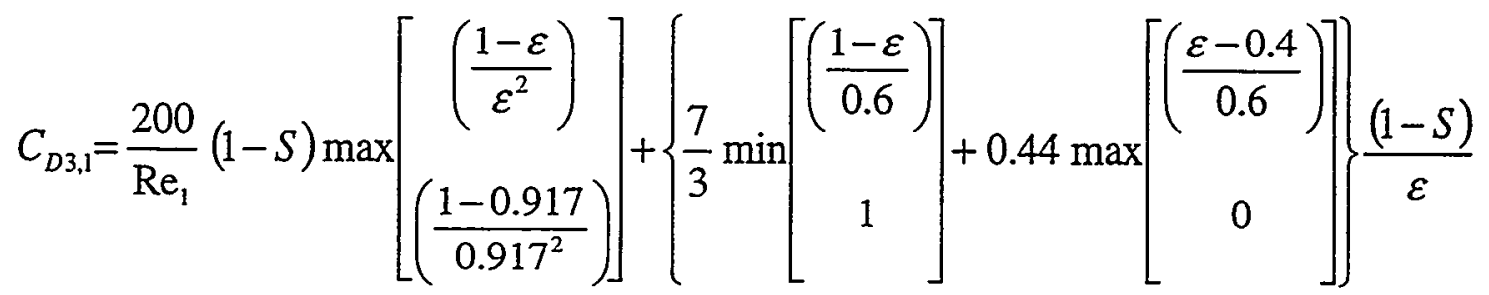

$$
\begin{aligned}
& C_{D 3.2}=\frac{200}{\operatorname{Re}_{2}} S \max \left[\begin{array}{c}
\left(\frac{1-\varepsilon}{\varepsilon^{2}}\right) \\
\left(\frac{1-0.917}{0.917^{2}}\right)
\end{array}\right]+\left\{\frac{7}{3} \min \left[\begin{array}{c}
\left(\frac{1-\varepsilon}{0.6}\right) \\
1
\end{array}\right]+0.44 \max \left[\begin{array}{c}
\left.\left(\frac{\varepsilon-0.4}{0.6}\right)\right) \\
0
\end{array}\right]\right\} \frac{S}{\varepsilon}
\end{aligned}
$$

The Reynolds numbers in Eq. (4.13) are based upon the interstitial velocities of each fluid.

$$
\begin{aligned}
& \operatorname{Re}_{1}=\frac{G_{1} D}{\mu_{1} \varepsilon(1-S)} \\
& \operatorname{Re}_{2}=\frac{G_{2} D}{\mu_{2} \varepsilon S}
\end{aligned}
$$

Equations (4.13) and (4.14) are used in IFCI.

\subsubsection{Melt-Water/Vapor Drag for Large Melt Diameter}

When the effective melt diameter is "large," meaning greater than the cell size, then the meltmixture drag is computed using an effective friction diameter calculated from linear RayleighTaylor theory. The effective friction diarneter approach is used to compensate for a characteristic of the multifield method: since there is more than one velocity field at a given point in space, materials can interpenetrate, with the rate of penetration controlled by the interfield drag. This characteristic is usually considered one of the strengths of the multifield method, but requires that appropriate constitutive relations be used. In the case of the melt diameter being large, if the melt diameter were used in the usual drag coefficient formulation, then the penetration rate would be too high. Instead, a diameter characteristic of the interpenetration should be used. This friction diameter can be estimated if it is assumed that the interface geometry is a flat surface with interpenetrating "fingers." The size of the fingers can be estimated using linear RayleighTaylor theory [16], and this size can then be used as the friction diameter in the calculation of the drag coefficient. 
The friction diameter can be estimated as one-half the linear Rayleigh-Taylor wavelength,

$D_{\lambda}=\pi \sqrt{\frac{3 \sigma_{3}}{\rho_{3} a}}$

where

$D_{\lambda}=$ the friction diameter and

$a=$ the local acceleration at the melt-mixture interface.

The interface acceleration $a$ is calculated by using a Weber number-Bond number equivalence and assuming equilibrium between the drag and surface tension forces:

$a=\frac{3}{4} C_{f} \frac{\rho_{x}}{\rho_{3}} V_{r 3 x}^{2} \frac{1}{D_{\lambda}}$

where

$$
\begin{aligned}
\rho_{x}= & \text { the fluid mixture density }\left(\alpha_{1}^{\prime} \rho_{1}+\dot{\alpha} \rho_{2}\right) . \\
V_{r 3 x}= & \text { the relative velocity between the melt and the fluid mixture } \\
& {\left[\left(\alpha_{1}^{\prime} \rho_{1} V_{1}+\alpha_{2} \rho_{2} V_{2}\right) / \rho_{x}-V_{3}\right] }
\end{aligned}
$$

In IFCI, the drag coefficient $C_{f}$ is estimated as 1.0. The friction diameter is also constrained to be at least the Weber diameter, given by

$$
D_{w_{e}}=\frac{12 \sigma_{3}}{\rho_{x} V_{r 3 x}^{2}}
$$

The friction diameter is used in the calculation of both the interfacial area and the drag coefficient. The interfacial area is calculated as the maximum of the interfacial area as determined from the surface area transport and fragmentation routines, and a minimum interfacial mix area, obtained by approximating the additional finger surface area as that of a right circular cylinder of diameter $D_{\lambda}$ and length $2.25 D_{\lambda}$. This results in an increase in the effective surface area by a factor of 3.25 . The drag coefficient is calculated as

$$
C_{D 3 x}= \begin{cases}1.0 & ; \operatorname{Re} \leq 80 \\ \frac{2}{3}\left(\frac{50}{\operatorname{Re}}+0.875\right) & ; \operatorname{Re}>80\end{cases}
$$


where the effective Reynolds number is found as

$\operatorname{Re}=\frac{\rho_{x} D_{\lambda} V_{r}^{2}}{\mu_{x}}$

where

$$
\mu_{x} \quad=\text { the mixture viscosity }\left(\alpha_{1}^{\prime} \mu_{1}+\alpha_{2}^{\prime} \mu_{2}\right)
$$

The above large-diameter interfacial friction coefficients are based on drag between melt and a water-vapor mixture. IFCI assumes that the friction coefficients for the separate water and vapor phases are equal to the mixture friction coefficient weighted by the volume fraction of the appropriate phase, giving

$C_{13}=C_{D 3 x} \frac{\alpha_{v}^{\prime} \rho_{1}}{\rho_{x}}$

and

$C_{23}=C_{D 3 x} \frac{\left(1-\alpha_{v}^{\prime}\right) \rho_{2}}{\rho_{x}}$

where the $z$ and $r$ subscripts have been omitted from the friction coefficients.

\subsection{Water-Vapor Interfacial Friction Coefficients}

Two flow regimes are considered in the water-vapor interaction. The bubbly flow regime exists when the liquid is the continuous phase and vapor exists in the form of bubbles. In the absence of a melt phase $\left(\alpha_{3}=0\right)$, the bubbly flow regime is defined by $\alpha_{1}<0.25$. In the "mist" flow regime, the vapor is the continuous phase, and the liquid takes the form of drops. In the absence of a melt phase $\left(\alpha_{3}=0\right)$, the "mist" flow regime is defined by $\alpha_{2}<0.25$. In the absence of rigid walls, there is no classically defined flow regime between these two limits. Therefore, this intermediate zone will be handled by interpolation between the bubbly and mist regimes.

When the melt phase is present, the definition of the flow regime boundaries must change. We borrow the definition of "saturation" from the packed-bed lexicon [Eq. (4.12)]. The flow regime will be considered "bubbly" when the saturation is greater than $0.75(S>0.75)$. The flow regime will be considered "mist" when the saturation is less than $0.25(S<0.25)$. 
The approach follows that of Ishii and Chawla [17]. The basic assumptions inherent in this formulation are as follows:

1. The interfacial drag on bubbles can be represented with the correlations commonly used for solid spherical particles, assuming no bubble distortion.

2. The transient is sufficiently slow that interfacial drag phenomena are quasi-steady. As a result, the transient forces during the acceleration of bubbles (apparent mass and Basset force) can be neglected.

3. The bubble diameter used for bubbly flow can be determined using a Weber number criterion.

The approach can be derived by first expressing the interfacial drag force between the liquid and the vapor $\left(\right.$ in $\mathrm{N} / \mathrm{m}^{3}$ ) as

$$
M_{1,2}=\frac{\alpha_{1} F_{b}}{\operatorname{vol}_{b}}
$$

where

$\alpha_{1} \quad=$ field 1 (vapor) volume fraction,

$F_{b} \quad=$ the drag force on a single bubble (newtons),

$\operatorname{vol}_{b}=$ the volume of a single bubble, $\operatorname{vol}_{b}=\frac{1}{6} \pi D_{b}^{3}$, and

$D_{b} \quad$ = bubble diameter.

Because this relation assumes steady-state conditions, the force on the bubbles is caused by skin friction and form drag only. The transient forces that occur during bubble acceleration (apparent mass and the Basset force) are neglected. The drag force can thus be written in terms of a spherical drag coefficient (of a bubble) as

$$
F_{b}=\frac{1}{2} C_{D b} \rho_{2} V_{r 1,2}\left|V_{r 1,2}\right| A_{P b}
$$

where

$C_{D b} \quad=$ bubble drag coefficient [see Eq. (4.13)],

$\rho_{2} \quad=$ density of the liquid,

$V_{r 1,2}=$ relative velocity between vapor and liquid $\left[V_{r 1,2}^{2}=\left(W_{2}-W_{1}\right)^{2}+\left(U_{2}-U_{1}\right)^{2}\right]$, and

$A_{P b}=$ projected area of the bubble, $A_{P b}=\frac{1}{4} \pi D_{b}^{2}$. 
In this case, the Reynolds number used to calculate the bubble drag coefficient is

$$
\operatorname{Re}_{b}=\frac{\rho_{2}\left|V_{r l, 2}\right| D_{b}}{\mu_{2}}
$$

To determine the diameter of the bubble, a bubble Weber number of $\mathrm{We}_{b}=7.5$ is assumed. The Weber number, as used here, gives the balance of inertial and surface tension forces on the bubble under steady-state conditions and thus determines the minimum bubble diameter for the current water material properties (surface tension, density) and relative velocity. Thus we can write

$$
D_{b}=\frac{\sigma_{2} \mathrm{We}_{b}}{\rho_{2}\left(V_{r 1,2}\right)^{2}}
$$

where

$$
\begin{aligned}
\mathrm{We}_{b} & =\text { bubble Weber number, } \mathrm{We}_{b}=7.5, \text { and } \\
\sigma_{2}= & \text { surface tension of the water, calculated as a function } \\
& \text { of pressure and saturation temperature. }
\end{aligned}
$$

Combining Eqs. (4.22) and (4.23) with the relations for projected area and volume of a spherical bubble, we can write

$$
M_{1.2}=\frac{0.75 C_{D b} \alpha_{1} \rho_{2} V_{r 1.2}\left|V_{r 1.2}\right|}{D_{b}}
$$

From this relation it is clear that the interfacial friction coefficient for use in the IFCI momentum equations can be calculated as

$$
C_{z 12}, \text { or } C_{R 12}=\frac{0.75 C_{D b} \alpha_{1} \rho_{2}}{D_{b}}
$$

\subsubsection{Bubbly Flow Adjusted for the Presence of Melt $(S>0.75)$}

There do not appear to be any experimental data on the effect of a third component (melt) on bubbly flow. In the absence of such data, an interpolating heuristic rule is imposed. The liquid/vapor interfacial area is assumed to be proportional to the complement of the melt volume fraction $\left(\alpha_{3}\right)$. This makes the interfacial drag force $\left(\right.$ in $\mathrm{N} / \mathrm{m}^{3}$ ) 
$M_{1,2}=\frac{0.75 C_{D b} \alpha_{1} \rho_{2} V_{r 1,2}\left|V_{r 1,2}\right|}{D_{b}}\left(1-\alpha_{3}\right)$

and the interfacial friction coefficient

$C_{Z 12}$, or $C_{R 12}=\frac{0.75 C_{D b} \alpha_{1} \rho_{2}}{D_{b}}\left(1-\alpha_{3}\right)$

\subsubsection{Mist Flow (No Melt, $\alpha_{1}>0.75$ )}

The mist regime is considered to exist in two-phase flow when the vapor volume fraction, $\alpha_{l}$, is greater than 0.75 .

The basic assumptions inherent in the IFCI formulation are as follows:

1. The interfacial drag on droplets can be represented with the correlations commonly used for solid spherical particles, assuming no bubble distortion.

2. Calculated transients are sufficiently slow that interfacial drag phenomena are quasisteady. As a result, the transient forces such as the apparent mass and the Basset force are neglected.

3. The bubble diameter used for bubbly flow can be determined using a Weber number criterion.

4. Any film contribution to the interfacial drag that might occur is neglected.

Because the liquid is assumed to exist as spherical droplets, the mathematical development for the interfacial drag is almost identical to the development of the bubbly flow regime [Eqs. (4.2) through (4.7)]. The difference for droplet flow is that the dispersed phase is now the liquid, and the continuous phase is the gas. Thus the interfacial friction coefficient is given by

$$
C_{z 12}, \text { or } C_{R 12}=\frac{0.75 C_{D d} \alpha_{2} \rho_{1}}{D_{d}}
$$

where

$C_{D d}=$ droplet drag coefficient,

$\alpha_{2} \quad=$ volume fraction of the liquid,

$\rho_{1} \quad=$ density of the vapor, and

$D_{d} \quad=$ droplet diameter.

The droplet drag coefficient is found by applying Eq. (4.1), where the appropriate Reynolds number is 


$$
\operatorname{Re}_{d}=\frac{\rho_{1}\left|V_{r 1,2}\right| D_{d}}{\mu_{1}}
$$

To determine the droplet diameter, $D_{d}$, a constant droplet Weber number of $\mathrm{We}_{d}=4.0$ is assumed. Thus we can write

$$
D_{d}=\frac{\sigma_{2} W e_{d}}{\rho_{1}\left(V_{r l, 2}\right)^{2}}
$$

where

$\alpha_{2}=$ surface tension of the water, calculated as a function of pressure and saturation temperature.

According to Reference 5, p. 6-27, sensitivity tests on the effect of droplet Weber number have shown that variations between 2 and 12 did not strongly influence the results, although Hinze [18] recommended a value of 3.46. In IFCI we adopt the TRAC value of 4.0.

\subsubsection{Mist Flow Adjusted for the Presence of Melt $(S<0.25)$}

The same interpolating heuristic rule that is imposed for bubbly flow is also imposed for mist flow: the liquid/vapor interfacial area is assumed to be proportional to the complement of the melt volume fraction $\left(\alpha_{3}\right)$. This makes

$$
C_{Z 12} \text {, or } C_{R 12}=\frac{0.75 C_{D d} \alpha_{2} \rho_{1}}{D_{d}}\left(1-\alpha_{3}\right)
$$

\subsubsection{Interpolation Between Bubbly and Mist Flow}

The interpolated flow regime is considered to exist in vertical flow when the saturation, $S$, is in the range from 0.25 to 0.75 . In this regime, the interfacial friction coefficient is found by linearly interpolating between the values that would be calculated at the bottom edge of the bubbly flow regime $(S=0.75)$ and the top edge of the mist regime $(S=0.25)$.

The application of this approach can be illustrated as follows:

Step 1: Calculate two values for an interfacial friction coefficient, one corresponding to bubbly flow when $S=0.75\left(C_{\text {bubble }}\right)$, the other corresponding to mist flow when $S=0.25\left(C_{\text {drop }}\right)$. Applying Eqs. (4.11) and (4.12), we can write 
$C_{\text {bubble }}=0.75 \cdot \alpha_{1} \rho_{2} \frac{C_{D b}}{D_{b}}\left(1-\alpha_{3}\right)$

and

$C_{\text {drop }}=0.75 \bullet \alpha_{1} \rho_{1} \frac{C_{D d}}{D_{d}}\left(1-\alpha_{3}\right)$

Step 2: Interpolate between the values of $C_{\text {bubble }}$ and $C_{\text {drop }}$ to calculate the interfacial friction coefficient.

$C_{Z 12}$, or $C_{R 12}=f_{1} C_{\text {bubble }}+\left(1-f_{1}\right) C_{\text {drop }}$

where the interpolating function $f_{1}$ is defined as

$f_{1}=\frac{(S-0.25)}{0.75-0.25} ; 0.25<S<0.75$

The major difference between the method employed by IFCI and that used in the current version of TRAC is that TRAC uses a cubic interpolating function instead of a linear function (see Reference 5, p. 6-46).

\subsection{Numerical Implementation on the Staggered Grid}

The equations in Sections 2, 3, and 4 have been written in generic form without reference to how they are calculated within the framework of the numerical grid used. For example, because the momentum equations are solved on a staggered grid, some parameters must be found using a weighted average. In Figure 4-4, the staggered grid is illustrated together with the defined locations of some of the quantities required in the equations. Note that the velocities are defined on the edges of the finite difference cells while most of the other key parameters are defined at the cell centers. However, the momentum equations are not solved on the cell volumes, but are solved by using cell volumes whose boundaries are illustrated by the dashed lines in this figure.

Cell-centered values that must be averaged for use in the momentum equation include the volume fractions, $\alpha_{f}$, the densities, $\rho_{f}$, the fluid viscosities, $\mu_{f}$, and the liquid surface tension $\sigma$. They are found as follows (where $\phi$ represents any of the aforementioned variables):

$\phi_{f, j-1 / 2}=\frac{\phi_{f, j}+\phi_{f, j-1}}{2}$

and 


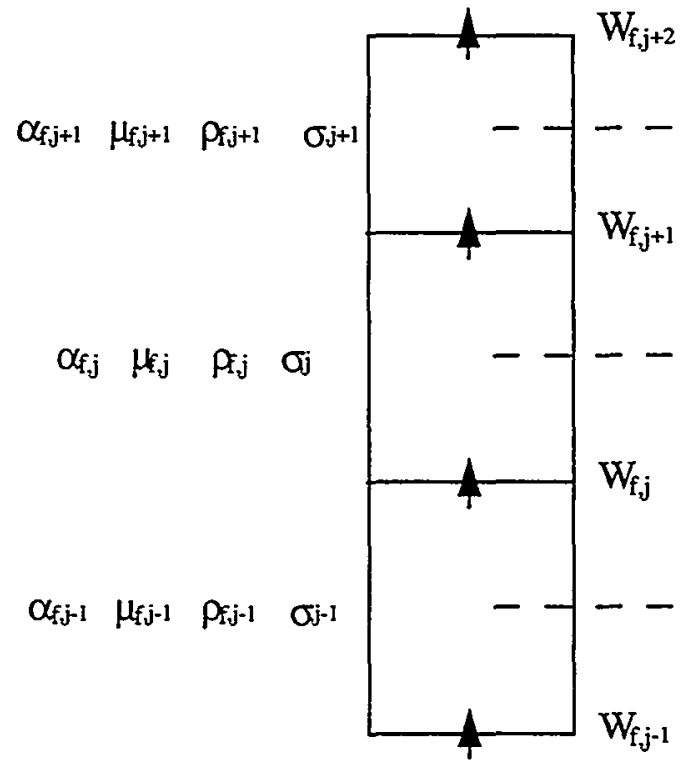

a. Axial momentum equation

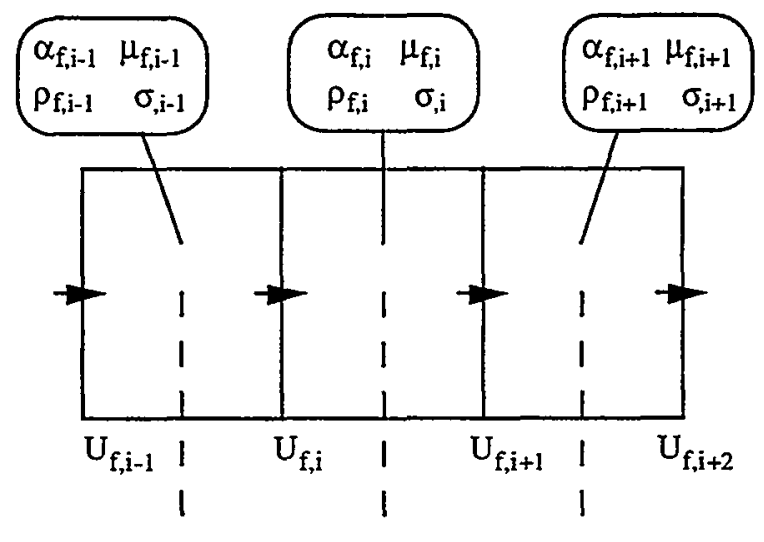

b. Radial momentum equation

Figure 4-4 Location of some key variables as needed in the finite-difference momentum equations solved by IFCI.

$\phi_{f, i-1 / 2}=\frac{\phi_{f, i}+\phi_{f, i-1}}{2}$

Note that the nomenclature used here designates that velocity $W_{f, j}$ be located at the cell boundary between the cell-centered parameters designated with the subscripts $j$ and $j-1$. For this reason, the weighted values of the cell-centered parameters that are used in the momentum equation for velocity $j$ are designated with the subscript $j-1 / 2$.

Additional key parameters calculated numerically and used in the momentum equations include the Reynolds numbers and the hydraulic diameter. These are calculated at locations consistent with the defined velocity locations. With respect to the numerical grid, they are always calculated as follows:

$\operatorname{Re}_{f, j}=\frac{\rho_{f, j-1 / 2} W_{f, j} D_{h, j}}{\mu_{f, j-1 / 2}}$ 


$$
D_{h, j}=\frac{4 \frac{\left(f_{\mathrm{vol} j}+f_{\mathrm{vol} j-1}\right)}{2}}{\frac{\left(S A_{j}+S A_{j-1}\right)}{2}}
$$

where

$$
\begin{aligned}
& f_{\text {volj }} \quad \text { = flow volume (nonstructure volume) of control volume } j\left(\mathrm{~m}^{3}\right) \text { and } \\
& S A_{j} \quad=\text { total wetted structure surface area within control volume } j\left(\mathrm{~m}^{2}\right)
\end{aligned}
$$




\section{INTERFIELD HEAT-TRANSFER MODELS}

As previously introduced, a conservation of energy equation [Eq. (2.4)] is solved for each fluid field. Of interest in this section is the fifth term in this equation-the heat transfer that can occur between different fluid fields existing together in the same local region (i.e., control volume).

\subsection{Heat Transfer Between Vapor (Field 1) and Water (Field 2)}

Originally, the two-phase (steam/ $\mathrm{H}_{2}$-liquid water) interfacial heat transfer models used in IFCI were primarily adopted from the TRAC-PF1/MOD1 computer code [5]. However, the flow regime map was simplified in order to be more applicable to fuel-coolant interactions (Section 3). Modifications to the TRAC-based correlations were made in order to be consistent with this revised flow regime map.

Section 5.1.1 describes the basic thermal energy implementation and the associated surface area calculations. Sections 5.1.2 and 5.1.3 describe the models and correlations applied for the bubbly and mist flow regimes, respectively. Section 5.1.4 describes the interpolation between the bubbly and mist flow regimes for two-component flows, and the interpolation used to extend to the presence of the melt. Finally, in Section 5.1.5 the major assumptions and simplifications made in the IFCI heat transfer modeling are summarized.

\subsubsection{Coefficients, Velocities, and Diameters}

Throughout this discussion of the two-phase interfacial heat transfer modeling in IFCI, a number of basic equations and definitions will be applied repeatedly. In this subsection, these parameters and definitions are defined and described, together with the associated correlations.

In IFCI, the heat transfer between the vapor and the water takes place at the vapor/water interface, which is assumed to exist at the saturation temperature $\left(T_{\text {sat }}\right)$. The heat loss from the liquid and from the vapor are, respectively:

$$
\begin{aligned}
& Q_{1 i}=h_{i 1} A_{12}\left(T_{1}-T_{\text {sat }}\right) \\
& Q_{2 i}=h_{i 2} A_{12}\left(T_{2}-T_{\text {sat }}\right)
\end{aligned}
$$

where

$Q_{1 i} \quad=$ the heat transferred from the vapor to the interface,

$Q_{2 i}=$ the heat transferred from the liquid to the interface,

$T_{\text {sat }}=$ the saturation temperature of steam evaluated at the partial pressure of the vapor,

$A_{12}=$ the interfacial surface area between the vapor and water,

$h_{\mathrm{i} 1}=$ the vapor-to-interface heat transfer coefficient, and

$h_{\mathrm{i} 2}=$ the interface-to-water heat transfer coefficient. 
The rate of evaporation (or condensation) is the sum of these two heats divided by the enthalpy of vaporization.

$$
M_{\text {evap }}=\frac{Q_{1 i}+Q_{2 i}}{L}
$$

where

$$
\begin{aligned}
& M_{\text {evap }}=\text { mass of water evaporated (or condensed if negative) and } \\
& L \quad=\text { enthalpy of vaporization. }
\end{aligned}
$$

Of great importance in calculating the interfacial heat transfer are a number of velocities associated with the different fields. These are described next.

Consider the control volume illustrated in Figure 5-1 and the water and vapor velocities shown. A cellcentered velocity difference between the water and vapor fields is calculated as follows:

Given the velocities as shown in Figure 5-1, average cell-centered water velocities are calculated and then used to find a vector water velocity, a vector vapor velocity, and a vector water-vapor velocity difference.

$$
\begin{aligned}
& \overline{W_{2}}=0.5\left(W_{2, j}+W_{2, j-1}\right) \\
& \overline{W_{1}}=0.5\left(W_{1, j}+W_{1, j-1}\right) \\
& \bar{U}_{2}=0.5\left(U_{2, j}+U_{2, j-1}\right) \\
& \bar{U}_{1}=0.5\left(U_{1, j}+U_{1, j-1}\right)
\end{aligned}
$$

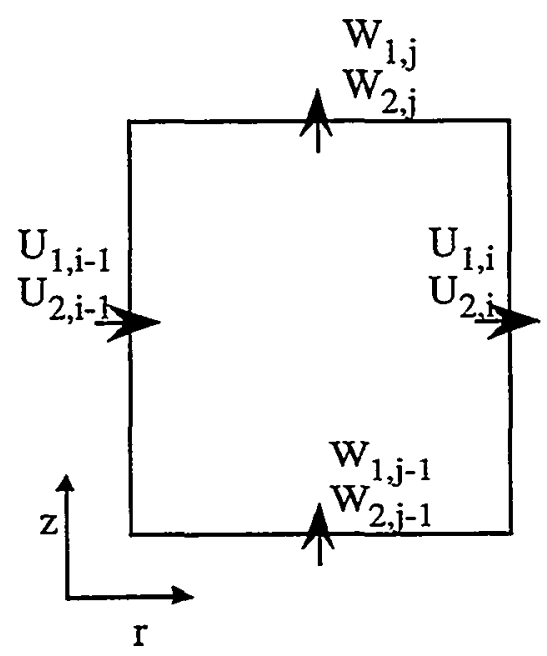

Figure 5-1 Water and vapor velocities around a typical control volume.

$$
V_{L}=\sqrt{\bar{W}_{2}^{2}+\bar{U}_{2}^{2}}
$$

$$
\begin{aligned}
& V_{V}=\sqrt{\bar{W}_{1}^{2}+\bar{U}_{1}^{2}} \\
& V_{12}=\max \left(\sqrt{\left(\bar{W}_{2}-\bar{W}_{1}\right)^{2}+\left(\bar{U}_{2}-\bar{U}_{1}\right)^{2}}, 10^{-3}\right)
\end{aligned}
$$


We next turn our attention to the calculation of droplet and bubble diameters. These are generally found by use of a constant Weber number assumption. In IFCI (as in TRAC), a constant value of 7.5 is used for bubbles, and a value of 4.0 for droplets. However, in IFCI this approach has been modified by the addition of a number of constraints that are intended to limit the possible values by physically based bounds. To describe the total approach, it is useful to list a number of equations and definitions.

First we note that by definition, the generic expression for the Weber number of a spherical bubble or droplet can be written as

$$
\mathrm{We}=\frac{\rho V_{r}^{2} D}{\sigma}
$$

where

$$
\begin{aligned}
& \sigma \quad \begin{array}{l}
\text { surface tension of the liquid phase (water), calculated as a function } \\
\text { of pressure and saturation temperature, }
\end{array} \\
& \rho \quad=\text { the density of the continuous fluid medium } \\
& D \quad=\text { the bubble or droplet diameter, and } \\
& V_{\mathrm{r}} \quad=\text { relative velocity between the vapor and water. }
\end{aligned}
$$

We now turn our attention to calculating a bubble diameter and bubble Reynolds number to be used in the bubbly flow and slug flow regimes. The physical situation envisioned is a mass of vapor bubbles surrounded by liquid water. We begin by defining a maximum bubble diameter:

$$
D_{b, \max }=\max \left[\min \left(D_{b, \text { rise }}, D_{b, \text { mass }}\right), D_{\min }\right]
$$

where

$$
\begin{aligned}
& D_{b . \text { rise }}=\sqrt{\frac{0.75 \mathrm{We} \sigma \rho_{1}}{\rho_{2} g\left(\rho_{2}-\rho_{1}\right)}} ; W e=7.5 \\
& D_{b \text {.mass }}=\left(\frac{6 \alpha_{1} \mathrm{vol}}{\pi}\right)^{1 / 3} \\
& D_{\text {min }}=0.0001 \mathrm{~m}
\end{aligned}
$$

The diameter, $D_{b, \max }$, is used in finding a bubble rise velocity, $V_{\text {rise, }}$ characterizing a bounding maximum velocity between bubbles and the surrounding water, if bubbles were rising under the 
force of buoyancy. Equation (5.9) is derived by assuming a Weber number of 7.5, a drag coefficient between the bubble and water of 1.0 , and balancing gravitational and drag forces. It is an upper bound because it does not account for viscous effects. Equation (5.10) is the diameter of a spherical bubble containing all of the vapor within the given control volume (vol $=$ the control volume), another physically based upper bound on the size of the bubble. The value of $D_{\min }$ given in Eq. (5.11) is an arbitrary lower limit (contained in a data statement in the code) that is applied.

Once the value of $D_{b, \max }$ is calculated from Eq. (5.8), the rise velocity, $V_{\text {rise, }}$ is calculated by assuming a drag coefficient between the bubble and water of 1.0, and balancing gravitational and drag forces [see Eq. (8.5) in Reference 19], yielding

$V_{\text {rise }}=\sqrt{\frac{4}{3} D_{b, \max } g\left(\frac{\rho_{2}-\rho_{1}}{\rho_{1}}\right)}$

This velocity is used as a lower bound on the relative velocity between the vapor bubble and the water, $V_{r b}$, used in calculating the bubble diameter, $D_{b}$, and bubble Reynolds number, $\operatorname{Re}_{b}$. Thus the following three equations are applied:

$$
\begin{aligned}
& V_{r b}=\max \left(V_{\text {rise. }}, V_{12}\right) \\
& D_{b}=\min \left[\max \left(\frac{\sigma \mathrm{We}_{\mathrm{b}}}{\rho_{2} V_{\text {rise }}^{2}}, D_{\min }\right) D_{b, \max }\right] ; \mathrm{We}_{b}=7.5 \\
& \operatorname{Re}_{b}=\frac{\rho_{2}\left|V_{r b}\right| D_{b}}{\mu_{2}}
\end{aligned}
$$

The bubble diameter is modified to correct for strongly superheated water conditions using the equation

$D_{b}=D_{b} e^{\frac{\left(T_{\mathrm{st}}\left(P_{10}\right)-T_{2}\right)}{20}}$

where $P_{\text {tot }}$ is the total pressure.

Another set of equations, completely analogous to Eqs. (5.8) through (5.15), is used to calculate a droplet diameter, $D_{d}$, and droplet Reynolds number, $\mathrm{Re}_{d^{*}}$. In this case we envision droplets of 
liquid water surrounded by gaseous vapor. Thus the idea of a terminal velocity is substituted for that of the rise velocity used above. Also, an additional constraint reducing the droplet diameter in superheated conditions is applied. These equations are given below in sequence, but without further explanation.

$D_{d, \text { max }}=\max \left\lfloor\min \left(D_{d, \mathrm{rerm}}, D_{d, \text { mass }}\right), D_{\min }\right\rfloor$

where

$D_{d, \mathrm{term}}=\sqrt{\frac{0.75 \mathrm{We} \sigma \rho_{2}}{\rho_{1} g\left(\rho_{2}-\rho_{1}\right)}} ; \mathrm{We}=4.0$

$D_{d, \text { mass }}=\left(\frac{6 \alpha_{2} \mathrm{vol}}{\pi}\right)^{1 / 3}$

$D_{\min }=0.0001 \mathrm{~m}$

$V_{\mathrm{term}}=\sqrt{D_{d, \max } g\left(\frac{\rho_{2}-\rho_{1}}{\rho_{2}}\right)}$

$V_{r d}=\max \left(V_{\text {term }}, V_{12}\right)$

$D_{d}^{\prime}=\frac{\sigma \mathrm{We}_{d}}{\rho_{1}\left(V_{\mathrm{term}}\right)^{2}} ; \mathrm{We}_{d}=4.0$

To adjust for superheated conditions, IFCI modifies the drop diameter using the equation

$D_{d}^{\prime \prime}=D_{d}^{\prime} e^{\left(\frac{T_{\text {sel }}\left(P_{100}\right)-T_{2}}{20}\right)}$ 
The droplet diameter and droplet Reynolds number are now calculated as

$D_{d}=\min \left[\max \left(D_{d}^{\prime \prime}, D_{\min }\right), D_{d, \text { mass }}\right] ; \mathrm{We}_{d}=4.0$

$\operatorname{Re}_{d}=\frac{\rho_{1}\left|V_{r d}\right| D_{d}}{\mu_{1}}$

Finally, given the values of the relative bubble velocity, $V_{r b}$, and the relative droplet velocity, $V_{r d}$, from Eqs. (5.13) and (5.21), the vector relative velocity, $V_{12}$, is bounded by these values:

$V_{12}=\max \left(V_{r b}, V_{r d}, V_{12}\right)$

\subsubsection{Bubbly Flow Regime}

For a saturation $(S)$ greater than 0.75 , correlations developed for the bubbly flow regime are used to determine the interfacial heat transfer.

\subsubsection{Interfacial Surface Area}

In bubbly flow, the interfacial surface area, $A_{12}$, is calculated in conjunction with a critical bubble Weber number as explained in Section 5.1.1. Given the value of $D_{b}$ [see Eq. (5.14)], and with the assumption of a uniform bubble distribution, the number of bubbles within the control volume $(\mathrm{CNB})$ is

$\mathrm{CNB}=\frac{6 \alpha_{1} \text { vol }}{\pi D_{b}^{3}}$

where $\alpha_{1}$ is the vapor volume fraction.

Assuming the bubble surface area can be found from the surface area of a sphere, the interfacial area can be found as

$A_{12-2 \mathrm{phase}}=6 \alpha_{1}\left(\frac{\mathrm{vol}}{D_{b}}\right)$ 
In TRAC, this value is restricted from becoming smaller than a value based on a minimum number density of bubbles. This restriction was removed from the IFCI formulation when situations arose that appeared to produce physically unreasonable results.

Equation (5.29) does not account for the presence of the melt. In IFCI, the liquid/vapor interfacial area is assumed to be proportional to the complement of the melt volume $\left(\alpha_{3}\right)$. Therefore,

$$
A_{12}=6 \alpha_{1}\left(\frac{V_{o l}}{D_{b}}\right)\left(1-\alpha_{3}\right)
$$

\subsubsection{Vapor-to-Interface Heat-Transfer Coefficient}

In the bubbly regime, the vapor-to-interface heat-transfer coefficient, $h_{i l}$, is set equal to a constant:

$h_{i 1}=1000$

This is a simplification of the TRAC formulation, which includes a different constant $\left(h_{i 1}=\right.$ $10,000)$ if the vapor temperature is in the nonequilibrium condition $T_{1}>T_{\text {sat }}$.

\subsubsection{Interface-to-Water Heat-Transfer Coefficient}

The interface-to-water heat-transfer coefficient is calculated using the heat-transfer coefficient for particulates. The Nusselt number for a single particle is $[20,11]$

$$
\mathrm{Nu}=2+0.459 \operatorname{Re}^{0.55} \operatorname{Pr}^{\frac{1}{3}}
$$

For a packed or fluidized bed, the Nusselt number is given by $[21,11]$

$$
\begin{aligned}
\mathrm{Nu} & =1.77 \varepsilon^{0.56}(1-\varepsilon)^{0.44} \operatorname{Re}^{0.56} \operatorname{Pr}^{\frac{1}{3}} \quad \text { if } \quad \operatorname{Re} \frac{\varepsilon}{1-\varepsilon}>30 \\
& =5.7 \varepsilon^{0.22}(1-\varepsilon)^{0.78} \operatorname{Re}^{0.22} \operatorname{Pr}^{\frac{1}{3}} \quad \text { if } \quad \operatorname{Re} \frac{\varepsilon}{1-\varepsilon}<30
\end{aligned}
$$

where the Reynolds number is based upon the interstitial velocity and $\varepsilon$ is the void fraction of the particulate bed. When applied to bubbly flow, the liquid volume fraction $\left(\alpha_{2}\right)$ is substituted for $\varepsilon$. 
The large Reynolds number portion of Eq. (5.33) very nearly corresponds to the large Reynolds portion of Eq. (5.32) for a void fraction $(\varepsilon)$ of 0.95 . The low Reynolds number portion of Eq. (5.33) is consistently lower than the value of 2 in Eq. (5.32) and displays a dependence upon the Reynolds number that does not disappear as the void fraction approaches unity.

The heat-transfer and mass-transfer data for gases in packed and fluidized beds consistently show values for Nusselt numbers that are substantially smaller than 2 for low Reynolds numbers [22]. The generally accepted explanation for this is the formation of microchannels that allow flow bypass of a portion of the particulates [23]. There has been only partial success in correlating low Reynolds data for gas flow [22].

It is not readily apparent that the microchannel mechanism is applicable in three-component flows. It is almost certain that the physical mechanisms would be modified by the presence of a third component. Therefore, in the absence of a better alternative, Eq. (5.33) is modified for IFCI:

$$
\mathrm{Nu}_{i 2}=\frac{h_{i 2} D_{b}}{k_{2}}=2+\max \left|\begin{array}{c}
1.77 \alpha_{2}^{0.56}\left(1-\alpha_{2}\right)^{0.44} \operatorname{Re}_{b}^{0.56} \operatorname{Pr}_{2}^{\frac{1}{3}} \\
1.77 \bullet 0.95^{0.56}(1-0.95)^{0.44} \operatorname{Re}_{b}^{0.56} \operatorname{Pr}_{2} \frac{1}{3}
\end{array}\right|
$$

\section{$\underline{\text { 5.1.3 Mist Flow Regime }}$}

The mist flow regime is considered to exist in vertical flow when the saturation $(S)$ is less than 0.25 . In IFCI, the interface-to-vapor Nusselt number, $\mathrm{Nu}_{i 1}$, is calculated similarly to the interface-to-water Nusselt number for bubbly flow [Eq. (5.34)] with the exception that the volume fraction of the steam $\left(\alpha_{1}\right)$ is substituted for $\varepsilon$ in Eq. (5.33):

$$
\mathrm{Nu}_{i 1}=\frac{h_{i 1} D_{d}}{k_{1}}=2+\max \left|\begin{array}{c}
1.77 \alpha_{1}^{0.56}\left(1-\alpha_{1}\right)^{0.44} \operatorname{Re}_{d}^{0.56} \operatorname{Pr}_{1}^{\frac{1}{3}} \\
1.77 \bullet 0.95^{0.56}(1-0.95)^{0.44} \operatorname{Re}_{d}^{0.56} \operatorname{Pr}_{1}^{\frac{1}{3}}
\end{array}\right|
$$

The interface-to-water heat-transfer coefficient, $h_{i 2}$, is calculated by assuming a constant Stanton number of 0.02 , but is limited to be no more than 50,000 .

$$
h_{i 2}=\min \left(50000,0.02 \rho_{2} C p_{2}\left|V_{\text {rel }}\right|\right)
$$

The interfacial surface is assumed to be proportional to the drop diameter and is further assumed to be proportional to the complement of the melt volume fraction. 


$$
A_{12}=6 \alpha_{2}\left(\frac{\mathrm{vol}}{D_{d}}\right)\left(1-\alpha_{3}\right)
$$

In determining the droplet diameter $D_{d}$, we note that a constant droplet Weber number of $\mathrm{We}_{d}=$ 4.0 is assumed. According to Reference 5 (see p. 6-27), sensitivity tests on the effect of droplet Weber number have shown that variations between 2 and 12 did not strongly influence the results, although Hinze [18] recommended a value of 3.46. In IFCI we adopt the TRAC value of 4.0.

\subsubsection{Transition Flow Regime}

The interpolated or transition flow regime is considered to exist in flow when saturation, is in the range from 0.25 to 0.75 . In this regime, the interfacial heat-transfer coefficients and surface areas are found by linearly interpolating between the values that would be calculated at the bottom edge of the bubbly flow regime $(S=0.75)$ and the top edge of the mist regime $(S=0.25)$.

The application of this approach can be illustrated as follows:

Step 1: Calculate two sets of values for the interfacial heat-transfer coefficients and surface areas, one set corresponding to bubbly flow when $S=0.75$, the other corresponding to mist flow when $S=0.25$. Applying Eqs. (5.38) through (5.43), we can write

$h_{i 1 . \text { bubbly }}=1000$, and

$h_{i 2 . \text { bubly }}=2+\max \left|\begin{array}{c}1.77 \alpha_{2}^{0.56}\left(1-\alpha_{2}\right)^{0.44} \operatorname{Re}_{b}^{0.56} \operatorname{Pr}_{2} \frac{1}{3} \\ 1.77 \bullet 0.95^{0.56}(1-0.95)^{0.44} \operatorname{Re}_{b}^{0.56} \operatorname{Pr}_{2} \frac{1}{3}\end{array}\right| \frac{k_{2}}{D_{b}}$

$A_{12, \text { bubly }}=6 \alpha_{1}\left(\frac{\mathrm{Vol}}{D_{b}}\right)\left(1-\alpha_{3}\right)$

and

$h_{i 2 \text {.mist }}=\min \left(50,000,0.02 \rho_{2} C p_{2}\left|V_{12}\right|\right)$ 


$$
\begin{aligned}
& h_{i 1, \text { mist }}=2+\max \left|\begin{array}{c}
1.77 \alpha_{1}^{0.56}\left(1-\alpha_{1}\right)^{0.44} \operatorname{Re}_{d}^{0.56} \operatorname{Pr}_{1}^{\frac{1}{3}} \\
1.77 \bullet 0.95^{0.56}(1-0.95)^{0.44} \operatorname{Re}_{d}^{0.56} . \operatorname{Pr}_{1}^{\frac{1}{3}}
\end{array}\right| \frac{k_{1}}{D_{d}} \\
& A_{12, \text { mist }}=6 \alpha_{2}\left(\frac{\mathrm{Vol}}{D_{d}}\right)\left(1-\alpha_{3}\right)
\end{aligned}
$$

Step 2: Interpolate between the set of values as follows:

$$
\begin{aligned}
& h_{i 1}=\left(1-f_{1}\right) h_{i 1, \text { mist }}+f_{1} h_{i 1, \text { bubbly }} \\
& h_{i 2}=\left(1-f_{1}\right) h_{i 1 \text {,mist }}+f_{1} h_{i 2, \text { bubbly }} \\
& A_{12}=\left(1-f_{1}\right) A_{12, \text { mist }}+f_{1} A_{12, \text { bubbly }}
\end{aligned}
$$

where the interpolating function, $f_{1}$, is defined as

$$
f_{1}=\frac{(S-0.25)}{0.75-0.25} ; 0.25<S<0.75
$$

We note that the difference between the interpolation method employed by IFCI and that used in the current version of TRAC is that TRAC uses a cubic interpolating function instead of a linear function.

\subsubsection{Review of Major Assumptions}

The models used in calculating the interfacial heat transfer coefficients and interfacial areas contain many fundamental assumptions. The major assumptions used are as follows:

1. It is assumed that the bubble and droplet diameters can be determined using a constant Weber number criterion. Such a model assumes an equilibrium between inertial and surface tension forces. For bubbles it is assumed that $\mathrm{We}_{b}=7.5$, for droplets that $\mathrm{We}_{d}=4.0$.

2. The transients are assumed to be slow enough that the flow regimes and the heat-transfer coefficients can be determined using a quasi-steady approach and the steady-state rise or terminal velocity. 
3. Bubbles or droplets are assumed to be uniformly distributed within the control volume.

4. Surface areas of bubbles and droplets can be found by assuming spherical geometry.

In addition to these five assumptions, each flow regime has assumed that certain correlations or constants are valid approximations for calculating the interfacial heat-transfer coefficients over the entire flow regime.

\subsection{Heat-Transfer Between Melt (Field 3) and Fields 1 and 2 (Vapor and Water)}

In IFCI, melt is assumed for heat transfer purposes to have the geometric character either of a collection of spherical particles each of diameter $D_{3}$ dispersed uniformly throughout the available flow volume, or of a horizontal pool surface. This section describes the heat transfer between melt particles and a surrounding water-vapor fluid.

When condensation is not being modeled, the heat-transfer rate between the melt and field $j$ ( $j=1$ or 2) is given by

$$
q_{3 j}=A_{3 j} h_{3 j}\left(T_{3}-T_{j}\right)
$$

where $A_{3 j}$ is the interfacial surface area between the melt and field $j$ per unit volume, and is calculated as follows:

$$
A_{3 j}=\frac{6 \alpha_{3}}{D_{3}} \bullet \begin{cases}(1-S) & \text { if } j=1 \\ S & \text { if } j=2\end{cases}
$$

where $S$ is the saturation. The focus of this section will be the determination of the heat transfer coefficients $h_{3 j}$.

Three different heat-transfer regions are described in Table 5.1. Both forced and natural convection are considered in region I. (However, it should be noted that not all this domain can be realized during reactor accidents.) In region $I$, nucleate, transition, and film boiling heattransfer regimes are modeled. Region $\mathrm{II}$ is a region where interpolation is applied so that the heat-transfer values behave smoothly as the flow conditions change from pure convection to boiling.

In the correlations that are applied, the important velocities will be relative velocities between the different fields. In particular, the velocity difference between the melt and water, and between the melt and vapor are important. These values are defined in IFCI in the same way that the relative velocities between fields 1 and 2 are [see Eqs. (5.3) through (5.6) and Figure 5-1]. 


$$
\begin{aligned}
& \bar{W}_{3}=0.5\left(W_{3, j}+W_{3, j-1}\right) \\
& \bar{U}_{3}=0.5\left(U_{3, i}+U_{3, i-1}\right) \\
& V_{13}=\max \left(\sqrt{\left(\bar{W}_{3}-\bar{W}_{1}\right)^{2}+\left(\bar{U}_{3}-\bar{U}_{1}\right)^{2}}, 10^{-3}\right) \\
& V_{23}=\max \left(\sqrt{\left(\overline{\bar{W}_{3}}-\bar{W}_{2}\right)^{2}+\left(\bar{U}_{3}-\bar{U}_{2}\right)^{2}}, 10^{-3}\right)
\end{aligned}
$$

\begin{tabular}{|c|c|c|}
\hline Region & Conditions & \\
\hline \multirow[t]{3}{*}{ I. Pure Convection } & $S<0.02$ & \\
\hline & $\left(T_{3} \leq T_{\text {sat }}\right.$, or $\left.T_{3} \leq T_{2}\right)$ & or \\
\hline & $P \geq P_{\text {crit }}$ & \\
\hline \multirow[t]{4}{*}{ II. Pure Boiling } & $S>0.25$ & or \\
\hline & $T_{3} \geq T_{\text {sat }}+5$ & or \\
\hline & $T_{3}>T_{2}$ & or \\
\hline & $\mathrm{P}<\mathrm{P}_{\text {crit }}$ & \\
\hline \multirow[t]{4}{*}{ III. Interpolation } & $0.02 \leq S \leq 0.25$ & or \\
\hline & $T_{\text {sat }}<T_{3}<T_{\text {sat }}+5$ & or \\
\hline & $T_{3}>T_{2}$ & or \\
\hline & $P<P_{\text {crit }}$ & \\
\hline
\end{tabular}

Table 5.1. Interfacial heat transfer regions for melt (field 3 ) in the presence of fields 1 and/or 2

\subsubsection{Pure Convection}

The melt-vapor and melt-water heat-transfer coefficients are calculated as an appropriate singlephase value weighted by a simple ( $\mathrm{ad}$ hoc) function of the saturation. 


$$
\begin{aligned}
& h_{31}=[1-\mathrm{f}(S)] h_{1} \\
& h_{32}=\mathrm{f}(S) h_{2}
\end{aligned}
$$

where

$f(S)=\max \left\{0, \min \left[1, \frac{(S-0.25)}{0.5}\right]\right\}$

Note that the function $\mathrm{f}(S)$ requires that the convective melt-vapor heat transfer be zero for $S$ above 0.75 , and the convective melt-water heat transfer be zero for $S$ less than 0.25 .

Both single-phase heat-transfer coefficients $\left(h_{31}\right.$ and $\left.h_{32}\right)$ are calculated using the same correlations, and both natural and forced convection regimes are considered. Using the subscript $\mathrm{f}$ to denote either the field 1 or field 2 coefficient, the correlations currently used in IFCI Reference 24, pp. 409-413) are as follows:

$\mathrm{Nu}_{f}=\frac{h_{f} D_{h}}{k_{f}}=\left\{\begin{array}{lr}\mathrm{Nu}_{n c} ; & \mathrm{r}=\mathrm{Gr} /(\mathrm{Re})^{2}>1 \\ \mathrm{r} \mathrm{Nu}_{n c}+(1-r) \mathrm{Nu}_{f c} ; \mathrm{r}=\mathrm{Gr} /(\mathrm{Re})^{2}<1\end{array}\right.$

where

$\mathrm{Nu}_{n c}=2.0+0.6 \mathrm{Gr}_{f}^{1 / 4} \operatorname{Pr}_{f}^{1 / 3}$

$\mathrm{Nu}_{f c}=2.0+\max \left|\begin{array}{c}1.77 \alpha_{f}^{0.56}\left(1-\alpha_{f}\right)^{0.44} \operatorname{Re}_{f}^{0.56} \operatorname{Pr}_{f}^{\frac{1}{3}} \\ 1.77 \bullet 0.95^{0.56}(1-0.95)^{0.44} \operatorname{Re}_{f}^{0.56} \operatorname{Pr}_{f}^{\frac{1}{3}}\end{array}\right|$

and where the Reynolds number, Grashof number, and Prandtl number are defined as

$$
\begin{aligned}
& \operatorname{Re}_{f}=\frac{\rho_{f} V_{f 3} D_{h}}{\mu_{f}} \\
& \mathrm{Gr}_{f}=\frac{\alpha_{f}^{2} g \beta_{f} D_{h}^{3}\left(T_{3}-T_{f}\right)}{v_{f}^{2}}
\end{aligned}
$$


$\operatorname{Pr}_{f}=\frac{\mu_{f} C p_{f}}{k_{f}}$

Note that the ratio $r=\mathrm{Gr} /(\mathrm{Re})^{2}$ determines the importance of natural convection in each case.

\subsubsection{Pure Boiling}

Heat-transfer coefficients that account for boiling are calculated whenever the melt temperature, $T_{3}$, is greater than $T_{\text {sat }}$ and the saturation, $S$, is greater than 0.02 . However, as will be described in detail in Section 5.2.3, interpolation is used when $T_{\text {sat }}<T_{3}<\left(T_{\text {sat }}+5\right)$ and when $0.02 \leq S \leq 0.25$. When $T_{3} \geq T_{\text {sat }}+5$ and $S>0.25$, the correlations discussed in this section are used without modifications.

Depending on the temperature of the melt, either nucleate, transition, or film boiling is considered to be occurring. Nucleate boiling occurs when the melt temperature is greater than $T_{\text {sat }}$ but less than $T_{C H F}$, the temperature corresponding to the critical heat flux. Film boiling is modeled when the melt temperature is greater than $T_{\min }$, the minimum film boiling temperature. Transition boiling is modeled in the intermediate range $T_{C H F}<T_{3}<T_{\min }$. In each of these regimes, a heat-transfer coefficient between the melt and both the liquid water, $h_{32}$, and gaseous vapor, $h_{31}$, must be calculated.

\subsubsection{Nucleate Boiling}

Nucleate boiling between melt and a two-phase steam-water mixture is modeled in IFCl in much the same way as described in Reference 4 for the TRAC code as it existed in 1986. Although some modifications to this approach have been made in TRAC, the material presented in Reference 5 is also largely still applicable to IFCI. The discussion here is adopted from References 4 and 5 and will only review the basis of this model as applied in the HTMELT subroutine.

\subsection{Melt-to-Water Heat Transfer Coefficient, $h_{32}$}

The Chen correlation (see Reference 25, p. 262) is used in the nucleate-boiling heat-transfer regime. The Chen correlation assumes that both nucleation and convective mechanisms occur and that the contributions made by the two mechanisms are additive.

$$
h_{32}=h_{f c}+\min \left[1, \frac{\left(T_{3}-T_{s a t}\right)}{\left(T_{3}-T_{2}\right)}\right] h_{n, b}
$$


The forced convective component, $h_{f c}$, is assumed to be represented by the maximum of a DittusBoelter type of turbulent flow equation (modified by the so-called $F$ factor) and the RohsenowChoi laminar flow equation.

$h_{f c}=\max \left\lfloor h_{t f c}, h_{1 f c}\right\rfloor$

where

$h_{1 f c}=4.0 \frac{k_{2}}{D_{c}}$

and

$h_{f c c}=0.023 \frac{k_{2}}{D_{c}}\left[\frac{\rho_{2} V_{23}\left(1-\alpha_{v}^{\prime}\right) D_{c}}{\mu_{2}}\right]^{0.8} \operatorname{Pr}_{2}^{0.4} F$

The parameter $F>1.0$ is used to modify the convective part of the correlation (called the "macroterm"), to account for increased agitation caused by the formation of vapor bubbles. The $F$ factor is found as a function of the Lockhart-Martinelli factor, $X_{T T}^{-1}$ :

$F= \begin{cases}1.0 ; & X_{T T}^{-1} \leq 0.10 \\ 2.35\left(X_{T T}^{-1}+0.213\right)^{0.736} & ; X_{T T}^{-1}>0.10\end{cases}$

with

$X_{T T}^{-1}=(\text { Martinellifactor })^{-1}=\left(\frac{x}{1-x}\right)^{0.9}\left(\frac{\rho_{2}}{\rho_{1}}\right)^{0.5}\left(\frac{\mu_{2}}{\mu_{1}}\right)^{0.1}$

and $X_{T T}^{-1}$ is limited to a maximum value of 100 .

The basis for the nucleate boiling component, $h_{n b}$, is the analysis by Forster and Zuber [26] for pool boiling. This has been modified by a suppression factor, $S u$, to account for the difference between the wall superheat and the mean superheat to which the bubble is exposed.

$h_{r b}=S u \cdot 0.00122\left(\frac{k_{2}^{0.79} C p_{2}^{0.45} \rho_{2}^{0.49}}{\sigma^{0.5} \mu_{2}^{0.29} L^{0.24} \rho_{1}^{0.24}}\right)\left(T_{3}-T_{\text {sat }}\right)^{0.24}\left(P_{w}-P\right)^{0.75}$ 
For values of $S>0.3$, the $S u$ factor is calculated as

$$
S u= \begin{cases}{\left[1.0+0.12\left(\operatorname{Re}_{t p}\right)^{0.14}\right]^{-1}} & ; 0.0<\operatorname{Re}_{t p}<32.5 \\ {\left[1.0+0.42\left(\operatorname{Re}_{t p}\right)^{p .78}\right]^{-1}} & ; 32.5 \leq \operatorname{Re}_{t p}<70\end{cases}
$$

where

$$
\operatorname{Re}_{t p}=\min \left[\left(\frac{\rho_{2} V_{23} S D_{c}}{\mu_{2}}\right) F^{1.25}, 70.0\right]
$$

Because the equation for the suppression factor (Eq. (5.68)) does not approach the correct limit of zero as the saturation approaches zero, an additional modification is imposed for values of $S$ less than 0.3. To ensure that $S u$ approaches the correct value for $S=0.0$, the following procedure is used. When $S<0.3, S u$ is evaluated at $S=0.3$ and the current value of $S$; the minimum of the two values, $S u_{\min }$, is saved. Linear interpolation is then used between the two values, $S u_{\min }$ and $S u=0.0$ at $S=0.02$. That is,

$$
S u= \begin{cases}S u_{\min } \frac{(S-0.02)}{(0.3-0.02)} ; & S<0.30 \\ 0.0, & S>0.02\end{cases}
$$

\subsection{Melt-to-Vapor Heat-Transfer Coefficient, $h_{31}$}

The melt-to-vapor convective heat-transfer coefficient is calculated to go from zero at $T_{3}=T_{\text {sat }}$ to the transition boiling value at $T_{3}=T_{C H F}$. It is defined as follows:

Let

$$
y=\frac{\left(T_{3}-T_{\text {sat }}\right)}{\left(T_{C H F}-T_{\text {sat }}\right)}
$$

then

$$
h_{31}=\left(3 y^{2}-2 y^{3}\right) h_{31, \mathrm{film}}\left(T_{C H F}\right)
$$


where $h_{31, \text { film }}\left(T_{C H F}\right)$ is found from the film boiling correlations described in Section 5.2.2.3 when $T_{3}=T_{C H F}$.

\subsubsection{Transition Boiling}

The transition boiling regime spans the boiling surface between the critical heat flux (CHF) and minimum film boiling. In this model it is assumed that transition-boiling heat transfer is composed of both nucleate-boiling (wet-wall) and film-boiling (dry-wall) heat transfer. This is based on the understanding that at a given location the surface is wet part of the time and dry during the remainder of the time. Therefore, contributions to both the water and vapor heattransfer coefficients should exist for all conditions.

\subsection{Melt-to-Water Heat-Transfer Coefficient, $h_{32}$}

In IFCI, it is assumed that the heat transfer to the liquid water from the melt can be approximated as an interpolation between the critical heat flux $\left(q_{C H F}\right)$ and the minimum stable film-boiling heat flux $\left(q_{\min }\right)$. The value for the film-boiling heat flux is, however, modified to account for radiation heat transfer (denoted $q_{\min , \text { rad }}$ ). The interpolation equation applied is

$q_{3-\text { liq }}=f_{1} q_{C H F}+\left(1-f_{1}\right) q_{\text {min, rad }}=h_{32}\left(T_{3}-T_{2}\right)$

where

$f_{1}=\left(3 y^{2}-2 y^{3}\right)$

$y=\frac{\left(T_{3}-T_{\min }\right)}{\left(T_{C H F}-T_{\min }\right)}$

$q_{\text {min }, \mathrm{rad}}=q_{\min }+\left[\sigma \varepsilon \frac{\left(T_{3}^{4}-T_{2}^{4}\right)}{\left(T_{3}-T_{2}\right)}\left(T_{\min }-T_{2}\right)\right]$

(Note: $\sigma$ is the Stefan-Boltzmann constant and $\varepsilon$ is the emissivity with $\varepsilon=0.7$ ). Given values for $T_{3}, T_{\min }, q_{\min }, T_{C H F}$, and $q_{\mathrm{CHF}}$, and applying Eqs. (5.74) through (5.76), the value for $h_{32}$ can be calculated directly by rearranging Eq. (5.73) as 
$h_{32}=\frac{f_{1} q_{C H F}+\left(1-f_{1}\right) q_{\text {min, rad }}}{\left(T_{3}-T_{2}\right)}$

The methods for calculating the values of $T_{C H F}$ and $q_{C H F}$ are described separately in Section 5.2.2.4. Likewise, the methods for calculating the values of $T_{\min }$ and $q_{\min }$ are described in Section 5.2.2.5.

\subsection{Vapor Convective Heat-Transfer Coefficient, $h_{31}$}

In IFCI, it is assumed that the heat-transfer coefficient for vapor can be approximated by interpolating between the value obtained at the critical heat flux $\left(h_{31, C H F}\right)$ and the value obtained at the minimum stable film-boiling heat flux $\left(h_{31, \min }\right)$. The interpolation equation applied is

$h_{31}=f_{1} h_{31, C H F}+\left(1-f_{1}\right) h_{31, \text { min }}$

where the interpolating function $f_{1}$ is identical to the one given in Eqs. (5.74) through (5.76).

$f_{1}=\left(3 y^{2}-2 y^{3}\right)$

$y=\frac{\left(T_{3}-T_{\min }\right)}{\left(T_{C H F}-T_{\min }\right)}$

\subsubsection{Film Boiling}

\subsection{Melt-to-Water Heat-Transfer Coefficient, $h_{32}$}

The film-boiling heat-transfer coefficient from the melt to the liquid water is given as

$$
h_{32}=\max \left(h_{\text {free }}, h_{\text {force }}\right)+h_{\text {rad }}
$$

where $h_{\text {free }}$ and $h_{\text {force }}$ are subcooled boiling correlations from Dhir and Purohit [27],

$$
h_{\text {free }}=h_{\text {sat }}+h_{\text {nat }} \frac{\left(T_{\text {sat }}-T_{2}\right)}{\left(T_{3}-T_{\text {sat }}\right)}
$$


where $h_{\text {sat }}$ is given by the Bromley correlation [28],

$h_{\mathrm{sat}}=0.8\left[\frac{\rho_{1}\left(\rho_{2}-\rho_{1}\right) g k_{1}^{3} L_{12}}{\mu_{1} D_{c}\left(T_{3}-T_{\text {sat }}\right)}\right]^{0.25}$

( $L_{12}$ is the latent heat of water) and $h_{\text {nat }}$ is a natural convection correlation,

$h_{\mathrm{nat}}=0.9\left[\frac{\rho_{2}^{2} g C p_{2} \beta\left(T_{\mathrm{sat}}-T_{2}\right) k_{2}^{3}}{\mu_{2} D_{c}}\right]^{0.25}$

The heat-transfer coefficient $h_{\text {force }}$ is a combination of the Bromley saturated-boiling heat-transfer coefficient $h_{\text {sat }}$ (above) and a forced-convection heat-transfer correlation,

$h_{\text {force }}=h_{\text {sat }}+0.8 \sqrt{\operatorname{Re}}\left[1+\frac{k_{2}\left(T_{\text {sat }}-T_{2}\right)}{k_{1}\left(T_{3}-T_{\text {sat }}\right)}\right] \frac{k_{2}}{D_{c}}$

where

$\operatorname{Re}=\frac{S \rho_{2} V_{23} D_{c}}{\mu_{2}}$

The heat-transfer coefficient from the film interface to the bulk liquid water is given by a natural convection correlation or a forced convection correlation whichever is greater [24]

$$
h_{2 s}^{c}=\max \left(\mathrm{Nu}_{n c}, \mathrm{Nu}_{f c}\right) \frac{k_{2}}{D_{c}}
$$

where

$$
\begin{aligned}
& \mathrm{Nu}_{n c}=2.0+0.6 \mathrm{Gr}_{2}^{1 / 4} \operatorname{Pr}_{2}^{1 / 3} \\
& \mathrm{Nu}_{f c}=2.0+\max \left|\begin{array}{c}
1.77 \alpha_{2}^{0.56}\left(1-\alpha_{2}\right)^{0.44} \operatorname{Re}_{2}{ }^{0.56} \operatorname{Pr}_{2} \frac{1}{3} \\
1.77 \cdot 0.95^{0.56}(1-0.95)^{0.44} \operatorname{Re}_{2}{ }^{0.56} \operatorname{Pr}_{2} \frac{1}{3}
\end{array}\right|
\end{aligned}
$$


and where the Reynolds number, Grashof number, and Prandtl number are defined as

$$
\begin{aligned}
& \operatorname{Re}_{2}=\frac{\rho_{2} V_{23} D_{c}}{\mu_{2}} \\
& \mathrm{Gr}_{2}=\frac{g \beta_{2} D_{c}^{3}\left(T_{3}-T_{2}\right)}{v_{2}^{2}} \\
& \operatorname{Pr}_{2}=\frac{\mu_{2} C p_{2}}{k_{2}}
\end{aligned}
$$

The radiation component of the melt-to-water heat-transfer coefficient is found as

$$
h_{\mathrm{rad}}=\sigma \varepsilon \frac{\left(T_{3}^{4}-T_{2}{ }^{4}\right)}{\left(T_{3}-T_{2}\right)}
$$

\subsection{Melt-to-Vapor Heat-Transfer Coefficient, $h_{31}$}

In film boiling, the melt-to-vapor heat-transfer coefficient is currently set to zero. Note, however, that since the overall value of $h_{31}$ is a sum of a boiling part and a convection part, its total value may not be zero.

\subsubsection{Critical Heat Flux}

If one considers a typical boiling curve, as the temperature of the surface increases to a point higher and higher above the fluid saturation temperature, a point is reached where the effective heat-transfer coefficient begins to deteriorate due to vapor blanketing. This point on the curve can be characterized by either the surface temperature, $T_{C H F}$, or the heat flux, $q_{C H F}$, at that point. The critical heat flux (CHF) point has two purposes in relation to the IFCI boiling curve. First, the $\mathrm{CHF}$ point indicates the change from a nucleate boiling regime to a transition boiling regime. Second, the CHF point is used in the quadratic interpolation that gives the transition-boiling liquid-water heat-transfer coefficient. 


\subsection{Basis of the Model}

The critical heat flux prediction model used in IFCI was adopted directly from the TRAC code. The package consists of the Biasi correlation [29] with modifications at low mass velocities and high void fractions.

The Biasi correlation consists of taking the maximum of two equations, where one is typically appropriate for low quality, and the other for high quality. As applied in IFCI, it can be expressed as follows:

$q_{C H F}=10^{4} \max \left[q_{C H F, \text { g, }} q_{C H F, h q}\right]$

where

$$
\begin{aligned}
& q_{C H F, \downarrow q}=\frac{1883}{\left(D_{h}\right)^{n}|G|^{1 / 6}}\left(\frac{f_{p}}{|G|^{1 / 6}}-x\right) \\
& q_{C H F, h q}=\frac{3780}{\left(D_{h}\right)^{n}|G|^{0.6}} h_{p}(1-x)
\end{aligned}
$$

and

$$
\begin{aligned}
h_{p} & =-1.159+\frac{8.99 P}{10+P^{2}}+0.149 P e^{-0.019 P}, \\
f_{p} & =0.7249+0.099 P e^{-0.032 P}, \\
n & =0.4 \text { for } D_{h} \geq 1 \mathrm{~cm}, \\
n & =0.6 \text { for } D_{h}<1 \mathrm{~cm}, \\
D_{h} & =\text { hydraulic diameter }(\mathrm{cm}), \\
|G| & =\text { absolute value of the mass flux }\left(\mathrm{gm} \mathrm{cm}^{-2} \mathrm{~s}^{-1}\right), \\
P & =\text { pressure (bar), and } \\
x & =\text { equilibrium quality. }
\end{aligned}
$$

Note that because the Biasi correlation uses centimeter-gram-second (cgs) units, Eq. (5.94) has a multiplication factor of $10^{4}$ so that the units of $q_{C H F}$ in IFCI will be in watts per square meter.

Typically, Eq. (5.95) is the controlling correlation for low quality and Eq. (5.96) for high quality. However, the value of the switchover quality is not constant and varies between about 0.3 and 0.7 , depending upon the pressure.

Currently, IFCI uses the Biasi correlation for values of $\alpha_{1}$ less than 0.97. For $0.97<\alpha_{1}<0.98$, the code uses the value obtained at $\alpha_{1}=0.97$ : For $\alpha_{1} \geq 0.98, T_{C H F}$ is fixed at $0.5 \mathrm{~K}$ above $T_{\text {sat. }}$. 
The single-phase liquid correlations explained in Section 5.2.1 are used. Also, because the Biasi correlation tends to overpredict the data at mass fluxes lower than $200 \mathrm{~kg} /\left(\mathrm{m}^{2} \mathrm{~s}\right)$, the CHF for these conditions is evaluated by using the Biasi correlation with $|G|=200 \mathrm{~kg} /\left(\mathrm{m}^{2} \mathrm{~s}\right)$.

Once $q_{C H F}$ is obtained, the wall surface temperature corresponding to the CHF point, $T_{C H F}$, is calculated by using a Newton-Raphson iteration to determine the intersection of the heat flux found by using the nucleate-boiling heat transfer coefficient (HTC) and the CHF. An iteration is required because $T_{w}=T_{C H F}$ must be known to evaluate the Chen correlation; and, in turn, the Chen HTC must be known to calculate the wall temperature, i.e.,

$$
q_{C H F}=h_{C H F}\left(T_{w}-T_{\text {sat }}\right)
$$

The iteration equation for determining $T_{C H F}$ can be expressed as

$$
T_{C H F}^{n+1}=T^{n}{ }_{C H F}-\frac{\left(T_{C H F}^{n}-T_{s a t}-\frac{q_{C H F}}{h_{C H F}}\right)}{\left(1+\frac{q_{C H F}}{h_{C H F}^{2}} \frac{d h_{C H F}}{d T_{w}}\right)}
$$

where the superscript $n$ is the iteration counter, $h_{C H F}$ is the heat-transfer coefficient evaluated by using the Chen correlation, and $\frac{d h_{C H F}}{d T_{w}}$ is the derivative of the heat transfer correlation with respect to the wall temperature. Currently, $T_{C H F}$ is restricted to the range of

$$
\left(T_{\mathrm{sat}}+0.5\right) \leq T_{\mathrm{CHF}} \leq\left(T_{\mathrm{sat}}+100\right)
$$

\subsection{Assumptions and/or Approximations}

The CHF prediction in IFCI using the Biasi correlation is based upon the following assumptions:

1. The transient is slow enough that the CHF phenomenon is quasi-steady. This assumption allows the use of an empirical correlation based on steady-state data in order to model transient CHF.

2. CHF is a function only of the local thermal-hydraulic parameters, and the history effects are negligible.

3. CHF is not affected by the flow direction. Using this assumption, the mass flux $G$ in the original correlation is replaced by the absolute value of $G$ in the code implementation.

4. The Biasi correlation was originally written for round tubes. In IFCI it is assumed that the tube diameter may be replaced by the hydraulic diameter of the flow channel. 


\subsection{Scaling Considerations}

The Biasi correlation was developed for round tubes; however, Reference 30 suggests that its success in predicting the blowdown data in various tests indicates that it can be scaled to rodbundle geometry using a hydraulic diameter. Its validity in other geometric regimes has not been examined.

\subsection{Model as Coded}

The application of these correlations within the code is straightforward. The actual coding can be found in subroutines CHFM and CHF1M. We note that in Eq. (5.98) convergence is assumed if the absolute value of $\left(T_{C H F}^{n+1}-T_{C H F}^{n}\right)$ is less than 1.0, and a maximum of 10 iterations is allowed. If convergence does not occur, a message is printed and a nonfatal error occurs.

\subsection{Assessment}

The Biasi correlation is one of the more frequently referenced correlations in the literature. The results of a major assessment of this correlation were recently reported by Groeneveld et al. [31], in which the Biasi correlation was compared with approximately 15,000 steady-state water data points that are stored in the Chalk River Nuclear Laboratories' CHF data bank. Also, Leung [32] has compared the Biasi correlation with transient CHF data. A review of these results and an assessment of the TRAC implementation has been given in Reference 5.

A summary of the assessment given in Reference 5 is as follows. The Biasi correlation yields reasonable results when compared with steady-state and transient annular flow dryout-type CHF data. However, these authors note that the good comparison with the flow transient data was probably due to the fact that the database being considered only had flow transients resulting in an annular flow regime prior to reaching CHF. Three areas of limitation or deficiency were noted. First, the current approach cannot model subcooled or very low-quality departures from nucleate boiling. Second, the predictions at low mass fluxes $\left[|G|<200 \mathrm{~kg} /\left(\mathrm{m}^{2} \mathrm{~s}\right)\right]$ is an area in which there is very little information available, and further experimental CHF studies are required before confidence in the predictions can be obtained. Third, the high-void-fraction model needs further assessment even though it gives favorable results for rapid depressurization transients in which a sudden core voiding occurs.

Finally, Liles et al. also note that one must be aware of the limitations imposed by the quasisteady approach used. For example, applying the present model to rapid transients such as quenching, where the CHF prediction is needed to calculate the return to nucleate boiling while going from right to left on a typical boiling curve, may prove to be a problem. 


\subsubsection{Minimum Stable Film-Boiling Temperature}

The minimum stable film-boiling temperature, $T_{\min }$, is the intersection point between the transition- and film-boiling heat-transfer regimes. It is also used in the interpolation scheme for determining the transition-boiling heat flux.

\subsection{Basis of the Model}

In IFCI, the homogeneous-nucleation minimum stable film-boiling temperature correlation of Henry [33] is used. This approach was adopted directly from TRAC. It can be written as

$T_{\min }=T_{n h}+\left(T_{n h}-T_{2}\right) \sqrt{R}$

where

$R=\frac{(k \rho C p)_{2}}{(k \rho C p)_{w}}$

and $T_{n h}$ is the homogeneous-nucleation temperature. In Eq. (5.101), the subscript 2 indicates liquid properties and the subscript $w$ refers to wall properties. The homogeneous-nucleation temperature is calculated as

$$
\begin{aligned}
T_{n h}=705.44-\left(4.77 \times 10^{-2}\right) D P & +\left(2.3907 \times 10^{-5}\right) D P^{2} \\
& -\left(5.8193 \times 10^{-9}\right) D P^{3}
\end{aligned}
$$

where

$$
D P=3209.6-P
$$

In Eq. (5.103) the pressure $P$ is in units of pound-force per square inch atmospheric, and the temperature in Eq. (5.102) is in degrees Fahrenheit. In IFCI, the variable $P$ is converted to a temporary variable in British units, and $T_{n h}$ is converted to Kelvin after the equation is evaluated. We note that according to Reference 5, Eq. (5.102) originated in the COBRA-TF code. 


\subsection{Assumptions and/or Approximations}

No additional assumptions need be mentioned here beyond those implied in the previous section.

\subsection{Scaling Considerations}

There are no parameters in the correlation to account for scaling geometry or mass flux. Fluid pressure, temperature, and thermal properties and wall thermal properties are the only parameters in the correlation; no limits are specified for these parameters.

\subsection{Model as Coded}

The application of this correlation within the code is straightforward. The actual coding can be found in subroutine TMSFBM. As mentioned earlier, since in Eq. (5.103) the pressure $P$ is in units of pound-force per square inch atmospheric, and the temperature is in Fahrenheit units, a conversion needs to be made to make the units consistent. In IFCI, the variable $P$ is converted to a temporary variable in British units, and then $T_{n h}$ is converted to Kelvin after the equation is evaluated.

\subsection{Assessment}

In Reference 5, the predictions of this model are compared with the data of Cheng et al. [34]. Chen's experiment extends earlier work by Groeneveld and Steward [35] on separation of the effects of axial conduction and hydraulic transients and is run over a short-enough test section in a steady-state manner so that these data, along with those of Groeneveld, represent the only known forced convective true $T_{\min }$ data. Because no additional assessment work has been done in the IFCI development effort, the reader is referred to Reference 5 for the details of this comparison. In summary, a comparison of the TRAC (and thus IFC) $T_{\min }$ model with true $T_{\min }$ data shows that the prediction is reasonable but could stand improvement in light of the more recent data. The prediction is considered reasonable because it is much closer to the data than are the apparent $T_{\min }$ values often developed from reflood and blowdown experiments. From the comparisons presented, it appears that the current $T_{\min }$ model overpredicts the data at typical reflood conditions ( 0.1 to $0.4 \mathrm{MPa}$ ) by 100 to $150 \mathrm{~K}$ and underpredicts the data at typical blowdown conditions ( $7 \mathrm{MPa}$ ) by about 60 to $100 \mathrm{~K}$.

\subsubsection{Interpolation Regime}

The interpolation region covers the temperature range $T_{\text {sat }}<T_{3}<\left(T_{\text {sat }}+5\right)$. This region has been defined so that the heat-transfer values will behave smoothly as the flow conditions change from normal convection to boiling.

In this region, both the melt temperature, $T_{3}$, and the normalized vapor volume fraction, $\alpha_{v}^{\prime}$, are used as interpolation parameters. Over the interpolating temperature range, a linear interpolation scheme is used. 
$h_{h}=\left(\frac{T_{3}-T_{\text {sat }}}{5}\right) h_{j, \text { boiling }}+\left[1-\left(\frac{T_{3}-T_{\text {sat }}}{5}\right)\right] h_{j, \text { convection }}$

where $j$ refers to either vapor or water, and the coefficients $h_{1, \text { convection }}$ and $h_{1, \text { boiling }}$ are found as described in Sections 5.2.1 and 5.2.2, respectively.

For the vapor field, to interpolate over the region $0.75 \leq \alpha_{v}^{\prime} \leq 0.98$, a cubic interpolating function (for which the derivatives are zero at the endpoints) is used.

$h_{1}=F 1 h_{1, \text { boiling }}+(1-F 1) h_{1, \text { convection }}$

where

$F 1=(3-2 x) x^{2}$

$x=\frac{\left(0.98-\alpha_{v}^{\prime}\right)}{0.23}$

For the water field, a series-type interpolating function is used, i.e.,

$$
h_{2}=\frac{1}{\frac{F 1}{h_{2, \text { boiling }}}+\frac{(1-F 1)}{h_{2, \text { convecion }}}}
$$




\section{WATER-VAPOR PHASE CHANGE}

Mass transfer between the water and vapor fields is described by a simple bulk boiling model for the case of mass transfer between water and bubbles or water drops and vapor. This assumes the existence of an interface between the two fields at the saturation temperature:

$$
\Gamma_{12}=A_{12} \frac{h_{2 \text { sat }}\left(T_{2}-T_{\text {sat }}\right)-h_{1 s a t}\left(T_{1}-T_{\text {sat }}\right)}{H_{\mathrm{lg}}}
$$

Surface boiling at the melt surface is simulated by a subcooled boiling model,

$$
\Gamma_{3}=A_{3} \frac{h_{3 s a t}\left(T_{3}-T_{\mathrm{sat}}\right)-h_{2 s a t}^{c}\left(T_{2}-T_{\text {sat }}\right)}{H_{\mathrm{lg}}}
$$

Equation (6.2) is used to describe film boiling at the melt surface with either subcooled or saturated coolant. 


\section{MELT FRAGMENTATION AND SURFACE AREA TRANSPORT}

\subsection{Fragmentation Model}

The idea of a dynamic fragmentation model that calculates the characteristic melt diameter as a function of instantaneous hydrodynamic conditions was first proposed by Young et al. [36]. A model using this idea was later incorporated into a version of the TEXAS one-dimensional FCI code [37] by Chu and Corradini [38] using an empirical correlation derived from data obtained in the Sandia Fully Instrumented Test Facility (FITS) experiments [39]. The fragmentation model in IFCI is a version of a dynamic fragmentation model developed by Pilch [40] based on Rayleigh-Taylor instability theory and the existing body of gas-liquid and liquid-liquid drop breakup data.

The basic Pilch model describes the primary breakup of a drop via penetration by Rayleigh-Taylor waves, and is expressed as

$$
\frac{d D}{d t}=-\frac{\left(1-N^{-1 / 3}\right)}{T^{+}}\left|V_{\eta}\right| \varepsilon^{0.5}
$$

where

$$
\begin{array}{ll}
D & =\text { drop diameter } \\
N & =\text { number of initial fragments (3-5) } \\
V_{r} & =\text { relative velocity between the drop and the surrounding fluid } \\
T^{+} & =\text {dimensionless time }(1-1.25)
\end{array}
$$

This formulation was developed from the empirical observation that in high Weber number drop breakup experiments, the drop experiences primary breakup into 3-5 primary fragments in a dimensionless time $T^{+}$between 1 and 1.25. While primary breakup is occurring, smaller fingers continuously develop and break off, forming a cloud of droplets. This effect is included in IFCI via a surface entrainment model

$$
\frac{d S}{d t}=C_{0} C_{f}^{0.75} \frac{1}{D} W e^{0.25}\left|V_{r}\right| \varepsilon^{0.5}
$$

where $d S / d t$ is the surface entrainment rate per unit melt area, and $C_{0}$ is a constant 0.089 . A more detailed derivation of the fragmentation model and a comparison with experimental data can be found in Appendix B of Reference 3.

Equations (7.1) and (7.2) are used in the formulation of surface area source terms for a melt volumetric-surface-area transport equation, as described in Section 7.2. 
The drop breakup data from which Eqs. (7.1) and (7.2) were derived consisted of isothermal liquid-gas and liquid-liquid breakup data. It is assumed here that this correlation will also apply under boiling conditions. There is some justification for this assumption in the experiments of Greene et al. [41] in that the drag coefficients for heated (boiling) and isothermal (nonboiling) steel balls dropped into water were about the same. Since the drag coefficient is essentially unchanged, the model is assumed to hold for both boiling and isothermal systems. A more important effect of boiling on the overall breakup is to cause higher local relative velocities and pressure fluctuations, accelerating the breakup process. This effect is included via the use of local relative velocity, $v_{r}$, in the equations.

\subsection{Surface Area Transport}

In IFCI, the quantity convected with the melt (field 3 ) is surface area per unit volume (volumetric surface area) [8]. Therefore the fragmentation mechanisms described by Eqs. (7.1) and (7.2) are reformulated in terms of rate of change of surface area per unit cell volume. This surface area formulation allows treatment of jets, drops, and other more general flows. The conversion to the volumetric surface area generation rate requires a knowledge of the relation between volumetric surface area $A_{3}$ and characteristic diameter $D$. In the case of discrete drops, this is given by

$$
A_{3}=\frac{6 \alpha_{3}}{D}
$$

Differentiating the expression for volumetric surface area leads to an equation for the rate of change of $A_{3}$ in terms of the rate of change of diameter for the primary breakup model [Eq. (7.1)],

$\Gamma_{p}=\frac{d A_{3}}{d t}=-\frac{6 \alpha_{3}}{D^{2}} \frac{d D}{d t}=-A_{3} \frac{1}{D} \frac{d D}{d t}$

where $\Gamma_{p}=$ surface area source due to primary breakup $\left(\mathrm{m}^{2} / \mathrm{m}^{3}-\mathrm{s}\right)$. In the case of the surface entrainment rate per unit melt area, $d S / d t$, simply multiplying this rate by the volumetric melt area $A_{3}$ gives the volumetric entrainment rate $\Gamma_{e}$. These surface generation rates are used as surface area source terms in a continuity equation for $A_{3}$,

$$
\frac{\bar{o} A_{3}}{\partial t}+\nabla \cdot\left(\bar{V}_{3} A_{3}\right)=\Gamma_{p}+\Gamma_{e}
$$

After solving the surface area transport equation (7.5) for a time step, new values of the characteristic melt diameter are calculated from the new surface area by reversing the procedure in Eq. (7.3). The present formulation of the surface area transport allows only one melt 
characteristic diameter per cell, which is assumed to represent a mean value of the actual size distribution in the cell.

The primary fragmentation model is set up in IFCI by first calculating the rate of change of melt diameter. This is done by assuming that the flow regime is that of melt drops in a continuous fluid. An average fluid density is calculated for the water and vapor fields at the cell center as

$$
\bar{\rho}_{f}=\frac{\alpha_{1} \rho_{1}+\alpha_{2} \rho_{2}}{\alpha_{1}+\alpha_{2}}
$$

Average values of the axial and radial field velocities are then formed at the cell center by averaging the values at the cell edges,

$$
\begin{aligned}
& \bar{V}_{Z k}=\frac{1}{2}\left(V_{Z k, j, i}+V_{Z k, j-1, i}\right) \\
& \bar{V}_{R k}=\frac{1}{2}\left(V_{R k, j, i}+V_{R k, j, i-1}\right)
\end{aligned}
$$

where the subscripts $R$ or $Z$ refer to the axial or radial component, respectively; $k$ is the field; $j$ is the axial cell index; and $i$ is the radial cell index. The vector differences of the melt velocity and the other two fields are then formed as

$$
\begin{aligned}
& V_{13}=\sqrt{\left(\bar{V}_{Z 1}-\bar{V}_{z 3}\right)^{2}+\left(\bar{V}_{R 1}-\bar{V}_{R 3}\right)^{2}} \\
& V_{23}=\sqrt{\left(\bar{V}_{z 2}-\bar{V}_{23}\right)^{2}+\left(\bar{V}_{R 2}-\bar{V}_{R 3}\right)^{2}}
\end{aligned}
$$

The final relative velocity used in the fragmentation equation is then calculated as the massweighted average of the vector velocity differences:

$V_{r}=\frac{(\alpha \rho)_{1} V_{13}+(\alpha \rho)_{2} V_{23}}{(\alpha \rho)_{1}+(\alpha \rho)_{2}}$

The above expressions [Eqs. (7.1)-(7.4)] for rate of change of volumetric surface area in a cell due to Rayleigh-Taylor instabilities are then used as a source in the surface area transport equation. After the new surface area is calculated using the transport equation, the new melt diameter is obtained using the relation between diameter, volume fraction, and surface area. 


\section{OXIDATION}

When the molten material in a fuel-coolant interaction is a metal, oxidation of the metal can significantly affect both the coarse mixing and detonation phases of the interaction. Oxidation is an exothermic process that adds heat to the fuel and produces hydrogen. The energy produced by oxidation can dramatically augment the explosive force of an FCI. The hydrogen produced by the oxidation may become involved in a gas detonation at a later stage of the accident.

A schematic of the oxidation process for a single drop of fuel is shown in Figure 8-1. The fuel drop itself is composed of an outer layer of oxide and an inner core of metal. The drop is surrounded by a "primary" bubble of gas, composed of water vapor and hydrogen.

The water is vaporized at the liquid/gas interface. Water vapor diffuses to the outer oxide surface, where it dissociates into atomic oxygen and molecular hydrogen. The hydrogen diffuses away from the drop surface and mixes with water vapor. Smaller bubbles of this gaseous mixture are spawned at the trailing end of the "primary" bubble.

The atomic oxygen produced at the oxide surface diffuses through the oxide layer until it reaches the unoxidized metal. At this location, it combines with the metal and increases the extent of the oxide layer. The solubility and diffusion of oxygen within the metal phase can complicate the oxidation calculation. With the exception of zirconium, these effects are ignored in the IFCI oxidation models.

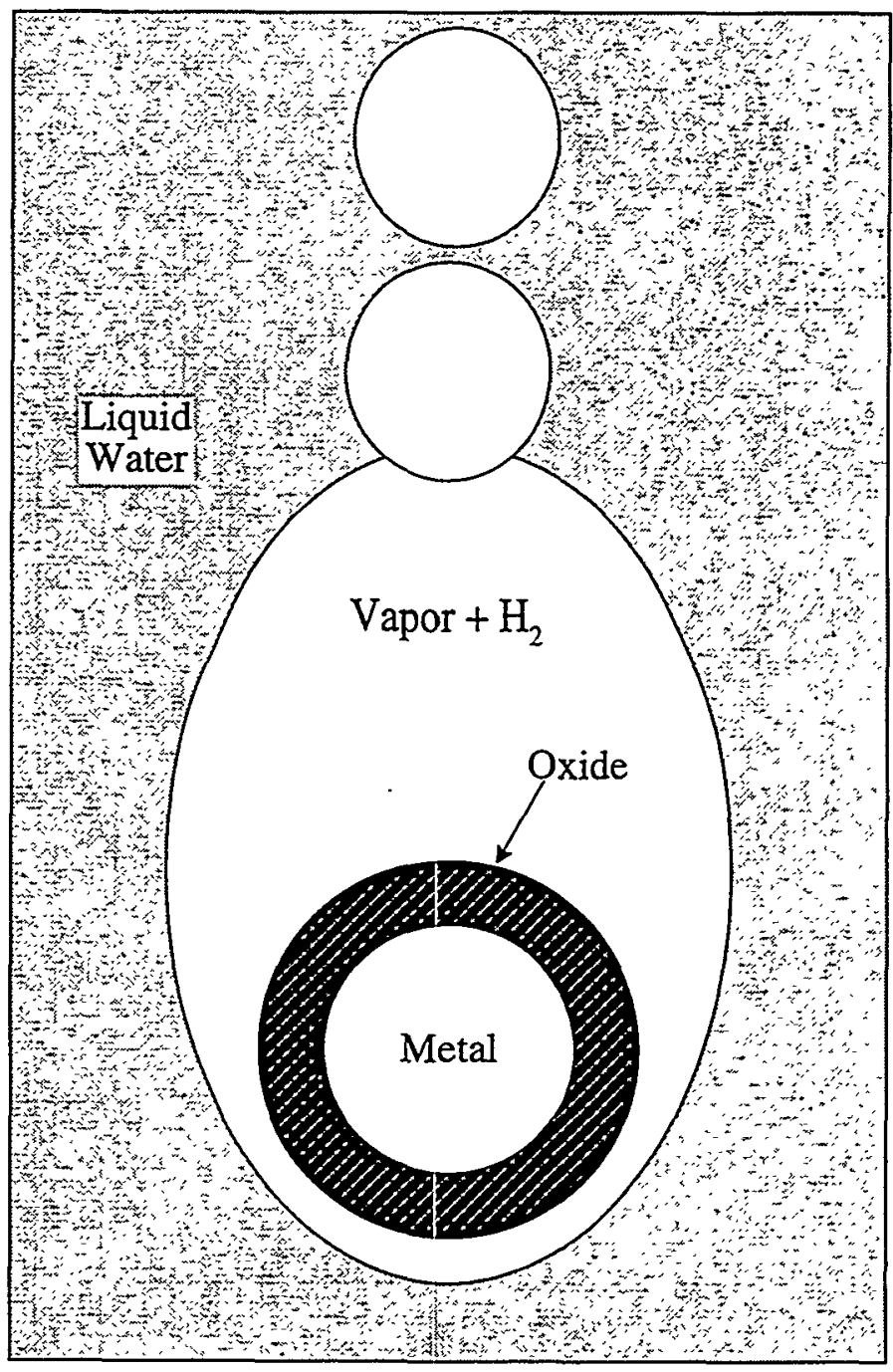

Figure 8-1 Oxidation of a single fuel drop in water

There are two possible limitations to the rate of oxidation. If there is sufficient atomic oxygen at the surface of the oxide, diffusion through the oxide layer is the controlling mechanism. However, the water vapor must diffuse across the vapor/hydrogen boundary layer before it dissociates. If the diffusion rate through this gaseous boundary layer is not sufficiently large, then the vapor/hydrogen diffusion can be the limiting mechanism. 


\subsection{Melt Oxidation-Hydrogen Production Model}

The oxidation model in IFCI is adapted from work by Pong [42], Young et al. [43], and Young [44]. The model considers oxidation in two water-steam flow regimes: continuous-steam flows and continuous-water or bubbly-flow in film boiling. Two melt geometries are considered: pool surface and droplets. This combination of flow regimes and geometries covers most situations where oxidation is likely to occur in reactor systems or experiments.

\subsubsection{Film-Boiling Oxidation}

If film boiling is occurring at the melt surface, IFCI uses an adaptation of the Pong model to determine the oxidation rate. Briefly, this model considers that a vapor film exists on the melt surface, that the film/water interface is at local saturation temperature and pressure, and that oxidation occurs at the melt/vapor interface due to steam generated at the film/water interface. The effect of depressed saturation temperature caused by hydrogen in the film reducing the steam partial pressure is included in the IFCI model. This effect increases the steam production rate at the film/water interface and therefore the maximum possible oxidation rate, subject to other limiting mechanisms.

In the Pong model, the equations for mass continuity, momentum, and energy are formulated as boundary-layer equations for the bulk coolant, film, and melt, and include an equation for the transport of hydrogen across the film. The Newton-Raphson technique is used to solve the equation set and gives a solution for the steam production rate and film thickness. The film parameters are used to get a maximum vapor-phase hydrogen mass-transfer rate at the melt/film interface, which is then used along with the relevant oxidation rate law to calculate hydrogen production and metal oxidation.

Pong [42] describes the complete equation set, which is the same as in Epstein et al. [45]. Briefly, the film, melt-drop, and bulk-water flows are approximated as those at the stagnation point of an impinging water flow on a flat plate (melt surface) with an overlying vapor film. The pressure distribution is assumed to be the same in the film as in the bulk water and is approximated by that due to potential flow around a sphere.

Reducing the boundary-layer equations in Pong [42] results in an equation for dimensionless film thickness at the stagnation point, $\eta_{\delta}$ [Eq. (41), Pong, 42],

$$
\frac{A}{\eta_{\delta}}+Q_{\mathrm{rad}}=\frac{1}{6} \eta_{\delta}^{3}-\frac{1}{2 \beta} \sqrt{C_{2}} C_{1} \eta_{\delta}^{2}+\mathrm{f}(0)+B \sqrt{\frac{1+C_{1}}{C_{2}}}
$$

where 


$$
C_{1}=\frac{0.25 \eta_{\delta}-\varepsilon}{\varepsilon+\sqrt{\frac{\pi}{2}} \frac{\eta_{\delta}}{\beta}} \quad C_{2}=\frac{\pi}{2}
$$

$f(0)$ is the dimensionless film momentum equation evaluated at $\eta=0$, [Eq. (36), Pong, 42],

$$
\mathrm{f}=\frac{-1}{12} \eta^{3}+\frac{1}{2} C \eta^{2}+\mathrm{f}(0)
$$

$C$ is defined as

$$
C=-\sqrt{\frac{\pi}{2}} \frac{C_{1}}{\beta}+\frac{\eta_{\delta}}{2}
$$

(Note that the sign on $C$ is wrong in Pong [42], p. 12.) $Q_{\mathrm{rad}}, A, B, \varepsilon$, and $\beta$ are dimensionless parameters defined as

$$
\begin{aligned}
& A=\frac{C\left(T_{w}-T_{i}\right)}{\operatorname{Pr} H_{l g}} \\
& B=\beta \frac{k_{l}}{k} \frac{\left(T_{i}-T_{\mathrm{c}}\right)}{\operatorname{Pr} H_{l g}} \sqrt{P r_{l}} \\
& Q_{\mathrm{rad}}=\frac{\dot{q}_{\mathrm{rad}}}{\sqrt{\frac{2 a}{v} H_{l g} v \rho}} ; \dot{q}_{\mathrm{rad}}=\sigma T_{w}{ }^{4} \\
& \beta=\left[\sqrt{\frac{\rho}{\rho_{l}}} \frac{v}{v_{l}}\right]^{0.5} \\
& \varepsilon=\sqrt{\frac{\rho}{\rho_{l}}} \\
& \eta=\sqrt{\frac{2 a}{v} z} \\
& a=\sqrt{\frac{\rho_{l}}{\rho} a_{l}}
\end{aligned}
$$


$a_{1}=3 \frac{V_{\infty}}{D}$

Equation (8.1) is solved together with the boundary conditions

$f(0)=\frac{Y_{i}\left(1-M_{g} / M_{v}\right)}{\operatorname{Sc} \eta_{\delta}}$

where

Sc $\quad=$ Schmidt number [see Eq. (8.20)],

$M_{g} \quad$ = the molecular weight of hydrogen

$M_{v} \quad=$ the molecular weight of hydrogen and steam, and

$Y_{i}=\left[1+\frac{1}{\operatorname{Sc} f\left(\eta_{\delta}\right) \eta_{\delta}}\right]^{-1}$

which give, respectively, the dimensionless steam velocity at the film/melt interface and the hydrogen molar concentration at the film/water interface. There are four dependent variables: $\eta_{\delta} f(0), Y_{i}$, and $T_{i}$, the film/water interface temperature. Closure requires a fourth equation, which is provided by assuming that $T_{i}$ is equal to the local saturation temperature of the film/water interface,

$$
T_{i}=T_{s}=\frac{4797}{\ln \left[\frac{3.8369 \times 10^{10}}{P_{\text {eq }}}\right]}
$$

where $P_{\text {eq }}$ is related to the local hydrogen concentration by

$$
\frac{P_{\mathrm{eq}}}{P_{\infty}}=\left[1+\left(\frac{1}{Y_{i}}-1\right) \frac{M_{v}}{M_{g}}\right]^{-1}
$$

\subsubsection{Solution Method}

In order to solve the above set of equations, a starting value of $T_{i}$ is selected by using the previous end-of-time step values for hydrogen concentration in Eq. (8.16). Equations (8.1), (8.13), and (8.14) are then solved for $\eta_{\delta} f(0)$, and $Y_{i}$ for this value of $T_{i}$, using a Newton-Raphson iteration. A new value of $T_{i}$ is calculated as

$$
T_{i}=0.5\left[T_{i}^{n}+T_{i}^{n+1}\right]
$$


where $T_{i}^{n+1}$ is the new value of the interface temperature calculated by Eq. (8.15) at the new $Y_{i}$. The iteration is repeated until the dependent variables converge to within a given relative error criterion.

The above procedure, with the $T_{i}$ outside the Newton-Raphson iteration and iterated as the average of the old and new saturation temperatures, is used for stability. Putting all four equations in the Newton-Raphson iteration seems to cause oscillations in $T_{i}$, which either never converges, or converges very slowly. As a point of interest, the partial derivatives in the Jacobian matrix for the Newton-Raphson procedure were derived using a symbolic mathematics package, Mathematica [46]. The resulting derivatives were output directly as Fortran source statements, eliminating any possibility of errors in deriving or coding the Jacobian matrix.

The output of the film-boiling model is the hydrogen concentration in the film and the film thickness. These variables are used as input to the diffusion-limiting model, which is described in Section 8.1.4.

\subsubsection{Mist Flow Model}

If the flow regime is mist flow, then the melt is assumed to be in contact with a steam-hydrogen vapor flow. Possible gas phase-limiting conditions in this regime are diffusion limits or steam availability in a finite-difference cell (a numerical restriction).

\subsubsection{Diffusion-Limiting Model}

The diffusion limit is calculated using the mass-transport analogue of the heat-transfer Nusselt number, which is formed by replacing the Prandtl number by the Schmidt number in the Nusselt correlation. In the present case, the equation used is either a sphere-based Nusselt number analogue [24, p. 409]

$$
\mathrm{Nu}_{x}=2+0.6 \mathrm{Sc}^{1 / 3} \operatorname{Re}^{1 / 2}
$$

if the melt is in the form of drops, or a flat-plate Nusselt analogue,

$$
\mathrm{Nu}_{x}=1+0.65 \mathrm{Sc}^{1 / 3} \mathrm{Re}^{1 / 2}
$$

if the melt is in the form of a pool. In the above two equations, the Reynolds number is based on the sphere diameter in Eq. (8.18) or on the cell hydraulic diameter in Eq. (8.19). Fluid properties are evaluated using the cell hydrogen concentration and cell vapor temperature. The Schmidt number $(\mathrm{Sc})$ is defined as

Sc $=\frac{\mu_{v}}{\rho_{v} D_{A B}}$ 
and the mass-transport Nusselt analogue is defined as

$$
\mathrm{Nu}_{x}=\frac{k_{x} d}{c D_{A B}}
$$

where

$$
\begin{array}{lll}
\mu_{v} & = & \text { vapor viscosity }(\mathrm{Pa}-\mathrm{s}) \\
c & = & \text { concentration of steam }\left(\mathrm{kmol} / \mathrm{m}^{3}\right) \\
\rho_{v} & = & \text { vapor density }\left(\mathrm{kg} / \mathrm{m}^{3}\right) \\
d & = & \text { characteristic length }(\mathrm{m}) \\
D_{A B} & = & \text { binary diffusion coefficient }\left(\mathrm{m}^{2} / \mathrm{s}\right) \\
k_{x} & = & \text { mass-transfer coefficient }\left(\mathrm{kmol} / \mathrm{m}^{2}-\mathrm{s}\right)
\end{array}
$$

The length $(d)$ in the equation for $\mathrm{Nu}_{x}$ is either the film thickness if in the film-boiling regime, or the minimum of the cell hydraulic diameter or melt drop size. The $k_{x}$ defines a maximum molar flux of steam at the reactive melt surface and is a possible limiting mechanism. This rate is applied to the melt reaction model.

\subsubsection{Reaction Model}

The melt-water reaction is governed by a rate law of the form

$$
\frac{d}{d t}\left(x^{n}\right)=n A e^{-B / T}
$$

where the exponent $n$ is 1 for a linear rate law (for example, initial steel oxidation), 2 for a parabolic (for example, zirconium oxidation laws), or 3 for cubic (aluminum oxidation); $x$ is the oxide thickness, or, alternatively, it can be thought of as the thickness of metal consumed. This rate law is integrated over a time step, giving an amount of metal consumed per unit metal area per time step. Given the stoichiometry for moles of steam consumed per mole of metal oxidized, the hydrogen produced per metal area per time step can be determined. There are currently oxidation models for four metals: (1) aluminum, (2) iron, (3) zirconium, and (4) 304 stainless steel. The specific rate equations used in IFCI are documented in Reference 42.

The rate laws cited in Reference 42 are for solid metals. Hydrogen production is usually accelerated somewhat when the metal is molten, but the oxide remains the dominant barrier to oxide diffusion. For this reason, the solid metal rate laws are applied to molten metals.

Hydrogen production increases dramatically when the oxide itself is molten. This is because the oxygen diffusivity of oxide increases greatly when the oxide melts. There are no reliable direct measurements of oxidation rate involving molten oxides, and a complete transport analysis of the oxygen is beyond the scope of IFCI. In addition, the oxidation rate above the oxide melting temperature is typically limited by vapor blanketing rather than diffusion through the droplet. To 
address this situation, the oxidation rate as calculated by the solid-metal rate law is increased by a factor of 10 . This is consistent with both the physics of oxidation and the structure of IFCI.

\subsubsection{Metal Distribution in Melt}

The hydrogen production for each metal must be related to the distribution of each metal in the melt. The above rate laws [Eq. (8.22)] give a hydrogen production rate per unit melt area. The cell variables concerned with the melt field available in the IFCI code are the melt mass, composition, and area.

The amounts of metal and oxide are used to define the fraction of melt area available for melt oxidation by forming the ratio of the volume of metal plus oxide to the total melt volume. This ratio is multiplied by the melt area to give an oxidation area for each metal-oxide pair. 


\section{NUMERICAL SOLUTION OF FIELD EQUATIONS}

The hydrodynamic field equations in IFCI are based on the multifield formulation of Ishii [8]. As mentioned previously, the solution method is a variation of the SETS method developed by Mahaffy [10]. The significant differences from the SETS method as described in Mahaffy are that (1) the momentum equations are formulated in conservative, rather than nonconservative, form (2) the momentum fluxes are corrected for diffusion using the flux-corrected transport (FCT) algorithm [47], and (3) fields with less than a specified small-volume fraction in a cell are solved via a separate "small- $\alpha$ " solver. This last is done to avoid numerical problems in the pressure iteration.

\subsection{SETS Solution Method}

In the variation of the SETS method used in IFCI, there are three main steps: the "predictor" step, the "basic" step, and the "stabilizing" step. -In the predictor step, the momentum equations are solved using old time step pressures to get predicted velocities. In the basic step, the velocities are expressed as functions of the new pressure $P$ and combined with the mass and energy equations to form a set of equations in the pressure only; these are then solved in a pressure iteration. The basic step provides the new pressure $P$, new velocities, volume fractions $\alpha_{k}$, and temperatures $T_{k}$. In the stabilizer step, the mass continuity and energy equations are solved using the new pressures for the quantities $(\alpha \rho)_{k}$ and $(\alpha \rho u)_{k}$, which are the macroscopic density and macroscopic internal energy for field $k$, respectively. These quantities will form the "old" time step values for the mass and energy equations in the basic step of the solution for the next time step.

\subsubsection{Predictor Step}

In the predictor step, the momentum equations are used to calculate estimated velocities for the new time step. "Predictor" momenta are calculated using old time step convective terms and pressures. Using old time step convective terms and pressures decouples the field momentum equations in each mesh cell from the neighboring cells, but the field-to-field coupling within a cell is treated implicitly, so that an $N \times N$ matrix is solved for a cell containing $N$ fields. The predicted masses are also calculated using explicit fluxes and phase-change terms.

It was found in the IFCI assessment that material fronts and shock fronts suffered from numerical diffusion. This is eliminated in the present method by correcting the momentum fluxes using an FCT algorithm. It is possible to correct the mass and energy fluxes also, but this was not found to give any improvement in the diffusion. The method used is a generalization of FCT due to Zaleszak [48]. The method can be briefly described as:

1. Calculate the mass and momentum transport fluxes using a low-order flux differencing method that is guaranteed to give monotonic results. In IFCI, this is donor cell differencing, 
and an artificial viscosity-like term is included in the momentum fluxes to give additional damping.

2. Calculate the transport fluxes using a high-order method. In IFCI, this is centered differencing.

3. Calculate the mass and momentum equations using the low-order fluxes.

4. Compute the antidiffusive flux as the difference between the high-order and low-order fluxes.

5. Apply a nonlinear limiter to the antidiffusive fluxes.

6. Apply the limited antidiffusive fluxes to the mass and momentum equations to get the corrected values of mass and momentum.

Dividing the predicted momenta by the predicted masses then gives the predictor velocities. Note: in the original SETS method, a stabilizer step was used here, in which the predictor velocities were used to decouple the fields within a cell; the momentum equations were then solved for each field over the entire problem using semi-implicit fluxes. This is not done in the present method, which means that the material Courant limit applies.

After obtaining the predictor velocities, the momentum equations are linearized to obtain equations describing the new time step velocities as linear functions of pressure. These equations are solved for each cell, using implicit drag terms, to obtain velocity coefficients giving the new velocities as functions of the pressure. The coefficients thus obtained are used to eliminate the velocities from the field equations, giving a set of equations involving only the cell variables $P, \alpha_{k}$, and $T_{k}$.

\subsubsection{Basic Step}

The basic step is a pressure iteration in which the new pressure $P$ is obtained by solving a global pressure matrix for the entire problem mesh. Looking back at the field equation set, there is a mass and an energy equation for each field in a cell, and a volume fraction constraint equation if more than one field is in the cell. This is a total of 10 equations per cell if all three fields are present. The field equations in a cell are only coupled to neighboring cells by the pressure $P$, via the velocity coefficients. The pressure solution is performed via a Newton-Raphson iteration using what is called the capacitance method. The capacitance method is a partitioning procedure that takes advantage of the fact that only the pressure is coupled from cell to cell to simplify the solution into three stages: (1) formation and inversion of the cell matrix (a 10x10 matrix if all fields are present, $2 \times 2$ if only one field is present), (2) formation and solution of the global pressure matrix (the dimension is the number of radial rings times the number of axial nodes in the problem mesh), and (3) back-substitution of the new pressures into the cell matrix to get the other new cell variables, $\alpha_{k}$ and $T_{k}$. The new velocities are also updated as part of the iteration.

The linearized, finite-differenced forms of the field equations plus the volume fraction constraint are first used to set up the Newton-Raphson pressure iteration equations by differentiating the mass continuity, energy, and volume fraction constraint equations with respect to the cell variables and the neighboring cell pressures. In general, the matrix form of the Newton-Raphson equations is 
$J \bullet \delta \mathrm{x}=-\mathbf{F}$

where

$\delta \mathbf{x}=$ vector of change in variables $\mathbf{x}$,

$\mathrm{F}=$ vector of functions (equations), and

$\mathbf{J}=$ Jacobian matrix of derivatives of the functions $\mathbf{F}$ with respect to the variables $\mathbf{x}$.

When the changes $\delta \mathbf{x}$ are solved for, the new values of the variables $\mathbf{x}$ are given by

$\mathbf{x}_{\text {new }}=\mathbf{x}_{\text {old }}+\delta \mathbf{x}$

In the present case, the variable vector $\mathbf{x}$ is the vector of cell variables $\left(P, \alpha_{1}, \alpha_{2}, \alpha_{3}, T_{1}, T_{2}, T_{3}\right)$, and the functions $\mathbf{F}$ are the mass, energy, and volume fraction constraint equations, plus the terms from the differentiated equations involving neighboring cell pressures. The form of the NewtonRaphson equation used is then

$\mathbf{J} \bullet \delta \mathbf{x}=-\mathbf{B}_{1} \delta P_{i, j}-\mathbf{B}_{2} \delta P_{i+1, j}-\mathbf{B}_{3} \delta P_{i-1, j}-\mathbf{B}_{4} \delta P_{i, j+1}-\mathbf{B}_{5} \delta P_{i, j-1}-\mathbf{S}$

where the terms are as defined before, and $\mathbf{S}$ is the residual of the field equations plus the alpha constraint. When this equation is inverted, the cell variable vector can be expressed as a function of the inverse Jacobian matrix $\mathbf{J}^{-1}$ times the right-hand-side terms. Only the first row of this matrix equation involves the cell pressure and neighboring cell pressures:

$\delta \mathbf{x}=-\mathbf{J}^{-1} \mathbf{B}_{1} \delta P_{i, j}-\mathbf{J}^{-1} \mathbf{B}_{2} \delta P_{i+1, j}-\mathbf{J}^{-1} \mathbf{B}_{3} \delta P_{i-1, j}-\mathbf{J}^{-1} \mathbf{B}_{4} \delta P_{i, j+1}-\mathbf{J}^{-1} \mathbf{B}_{5} \delta P_{i, j-1}-\mathbf{J}^{-1} \mathbf{S}$

The first rows of Eq. (9.4) are collected and assembled to form the global pressure matrix, which is then solved by a band-matrix solution method for the changes in pressure, $\delta P_{i, j}$. The pressure changes are then back-substituted into Eq. (9.4) to get the changes in the other cell variables. This algorithm constitutes one iteration of the pressure iteration. Convergence of the pressure iteration, indicated by all cell variable changes being less than a set of error criteria, ends the basic step.

\subsubsection{Stabilizer Step}

In the stabilizer step, the mass and energy equations are solved for the new time step quantities $(\alpha \rho)_{k}$ and $(\alpha \rho u)_{k}$, using the new pressures, velocities, and mass and energy transfer terms. This ends the solution of the field equations for one time step. 


\subsection{Small- $\alpha$ Solver}

The numerical problem of having small amounts of a field in a cell has been recognized since the SETS method was developed for use in multifield codes such as TRAC [4]. The usual procedure for dealing with small amounts of mass is to impose a low-volume fraction cutoff: fields with volume fractions less than this cutoff are not included in the set of cell variables and hence do not have mass and energy equations in the cutoff cell. Codes using the SETS method, such as TRAC, typically are run with cutoff volume fractions of $10^{-3}-10^{-5}$.

\subsubsection{The Numerical Problem}

The problem occurs during the inversion of the cell matrix; there is one mass and one energy equation for every field in a cell, as mentioned previously; however, when the amount of the field is very small, the rows in the cell matrix for this field's mass and energy equations are numerically very small compared with the other rows of the matrix, resulting in a near-singular cell matrix. This results in loss of precision in the pressure iteration, which cannot converge because the pressure changes in those cells with small amounts of mass are dominated by roundoff error.

Volume fraction cutoff levels of $10^{-3}-10^{-5}$ seem sufficiently high that roundoff error in the inversion of the cell matrix is not a problem when the model is run on a computer with a 64-bit word length (CRAY or double precision). However, the validation studies done with IFCI on mixing experiments demonstrate that these high values cause an artificial slowing down of, for instance, melt or solid balls dropping into water [49]. The calculated fall times and terminal velocities are then not correct.

This artificial retardation of material movement becomes less apparent for larger mesh cells because numerical diffusion due to finite differencing of the donor cell will then dominate. During the course of the IFCI validation studies done during fiscal year 1995 [49], the sensitivity of the problem simulation to mesh cell size was investigated. It was found that fairly fine meshing (cells $1-3 \mathrm{~cm}$ high) was necessary to reduce numerical diffusion effects enough to accurately simulate the fall time and mixing behavior observed in the experiments (MIXA, MAGICO, KROTOS). When small meshes are used, the retardation effect caused by the smallvolume fraction cutoff is significant unless the cutoff is reduced to the order of $10^{-16}$. At this level, when small-volume fractions are present, the cell matrix inversion experiences roundoff error significant enough to dominate the pressure solution. When the pressure changes are actually due to roundoff error, iteration does not result in convergence of the solution. The error is also fairly insensitive to reducing the time step, so the usual result is either a code crash or very long run times. 


\subsubsection{Modification of SETS Method}

The problem with small-volume fractions $(\alpha)$ in a cell can be alleviated by using a modified solution method. In this modification, the "small- $\alpha$ " field(s) are not included in the set of cell equations solved in the main Newton-Raphson step of the pressure iteration if the field volume fraction is below a second volume fraction cutoff, $\alpha_{\text {num. }}$. The second cutoff is set to a value high enough that numerical roundoff is not a problem (currently, $10^{-8}-10^{-10}$ ). However, the fields are "on" in the cell and their transfer terms are also "on." Since the small fields are not in the cell matrix, the cell matrix inversion and pressure solution proceed normally; after the main global pressure matrix solution part of the pressure iteration step, a procedure termed the "small- $\alpha$ solver" is used to update the small- $\alpha$ fields. This small- $\alpha$ solver solves the mass and energy equations for the small- $\alpha$ fields explicitly for the new values of $\alpha_{k}$ and $T_{k}$, based on the updated pressure $P$ and velocities from the main pressure matrix solution. This method avoids the numerical roundoff problem that occurs when the small- $\alpha$ fields are included as part of the cell matrices.

\subsection{Auxiliary Transport Equations}

In addition to the basic set of field equations, alpha constraint, equations of state, and constitutive relations, there is a set of auxiliary transport equations that must be solved for the vapor and melt field components. The vapor field consists of two components, steam and hydrogen. The melt field can have up to eight components. Mass continuity equations are solved for each component on each time step so that mass fractions may be updated for use in calculating field properties, such as heat capacity and density.

The auxiliary transport equations are solved in exactly the same manner as the field mass continuity equations. Since there are two places in the calculation where the continuity equations are solved-once in the predictor step and once in the stabilizer step-the auxiliary equations are also solved in these two steps. A solution that uses the same methods ensures that the sum of the field mass components will equal the total field mass from the field continuity solution. 


\section{REFERENCES}

1. M. F. Young, IFCI: An Integrated Code for Calculation of All Phases of Fuel-Coolant Interactions, SAND87-1048, NUREG/CR-5084, Sandia National Laboratories, Albuquerque, NM, 1987.

2. M. F. Young, "Application of the IFCI Integrated Fuel-Coolant Interaction Code to a FITS-Type Pouring Mode Experiment," in Dynamics of Detonations and Explosions: Explosion Phenomena, AIAA, Vol. 134, 1990.

3. F. J. Davis and M. F. Young, Integrated Fuel-Coolant Interaction (IFCI 6.0) Code User's Manual, NUREG/CR-6211, SAND94-0406, Sandia National Laboratories, Albuquerque, NM, 1994.

4. Safety Code Development Group, TRAC-PF1/MOD1: An Advanced Best Estimate Computer Program for Pressurized Water Reactor Thermal-Hydraulic Analysis, NUREG/CR-3858, LA-10157-MS, Los Alamos National Laboratories, Los Alamos, NM, 1986.

5. D. R. Liles, et al. , TRAC-PF1/MOD1 Correlations and Models, NUREG/CR-5069, LA11208-MS, R4, Los Alamos National Laboratories, Los Alamos, NM, 1988.

6. S. S. Dosanjh, MELPROG-PWR/MOD1: A Two Dimensional, Mechanistic Code for Analysis of Reactor Core Melt Progression and Vessel Attack Under Severe Accident Conditions, NUREG/CR-5193, SAND88-1824, Sandia National Laboratories, Albuquerque, NM, 1989.

7. R. C. Schmidt et al., MELPROG PWR/MOD1 Models and Correlations, SAND89-3123, NUREG/CR-5569, Sandia National Laboratories, Albuquerque, NM, 1992.

8. M. Ishii, Thermo-Fluid Dynamic Theory of Two-Phase Flow, Eyrolles, France, 1975.

9. G. Kocamustafaogullari, "Thermo-Fluid Dynamics of Separated Two-Phase Flow," Ph.D. dissertation, Georgia Inst. of Technology, Atlanta, GA, 1971.

10. J. H. Mahaffy, "A Stability-Enhancing Two-Step Method for Fluid Flow Calculations," J. Comp. Phys. Vol. 46, p. 329, 1982.

11. S. L. Soo, Fluid Dynamics of Multiphase Systems, Blaisdell Publishing, Waltham, MA, 1967.

12. A. E. Scheidegger, The Physics of Flow Through Porous Media, 3rd ed., University of Toronto Press, Toronto, 1974. 
13. R. J. Lipinski, A Model for Boiling and Dryout in Particle Beds, SAND82-0765, NUREG/CR-2646, Sandia National Laboratories, Albuquerque, NM, 1982.

14. A. W. Reed, "The Effect of Channeling on the Dryout of Heated Particulate Beds Immersed in a Liquid Pool," Ph.D. thesis, Massachusetts Institute of Technology, Cambridge, MA, 1982.

15. R. H. Brooks and A. T. Corey, "Hydraulic Properties of Porous Media," Hydrology Papers, Colorado State University, No. 3, 1964.

16. S. Chandrasekar, Hydrodynamic and Hydromagnetic Stability, Oxford University Press, 1971.

17. M. Ishii and T. C. Chawla, Local Drag Laws in Dispersed Two-Phase Flow, ANL-79-105, NUREG/CR-1230, Argonne National Laboratory, Argonne, IL, 1979.

18. Hinze, "Fundamentals of the Hydrodynamic Mechanism of Splitting in Dispersion Processes," AIChE J., Vol. 1 (3), pp. 289-295, 1955.

19. G. B. Wallis, One Dimensional Two-Phase Flow, McGraw-Hill, New York, 1969.

20. R. M. Drake, Jr., J. Heat Transfer, Trans. ASME, Vol. 83, p. 170, 1961.

21. J. C. Chu, J. Kalil, and W. A. Wetteroth, Chem. Eng. Prog., Vol. 49, p. 141, 1953.

22. D. Kunii and O. Levenspiel, Fluidization Engineering, Robert E. Krieger Publishing, Huntington, 1977.

23. S. S. Zabrodsy, Int. J. Heat Mass Transfer, Vol. 6, p. 23, 1963.

24. R. B. Bird, W. E. Stewart, and E. N. Lightfoot, Transport Phenomena, Wiley, New York, 1960.

25. J. C. Chen, "A Correlation for Boiling Heat Transfer of Saturated Fluids in Convective Flow," ASME paper 63-HT-34, 1963.

26. H. K. Forster and N. Zuber, "Bubble Dynamics and Boiling Heat Transfer," AIChE J., Vol. 1 , pp. 532-535, 1955.

27. V. K. Dhir and G. P. Purohit, "Subcooled Film-Boiling Heat Transfer from Spheres," Nuclear Eng. Design, Vol. 47, pp. 49-66, 1978.

28. L. A. Bromley, N. R. LeRoy, and J. A. Robbers, "Heat Transfer in Forced Convection Film Boiling," Ind. Eng. Chem., Vol. 45, pp. 2639-2646, 1953. 
29. L. Biasi, G. C. Clerici, S. Garribba, R. Sala, and A. Tozzi, "Studies on Burnout, Part 3: A New Correlation for Round Ducts and Uniform Heating and Its Comparison with World Data," Energia Nucleare, Vol. 14, pp. 530-536, 1967.

30. W. M. Rohsenow and H. Y. Choi, Heat, Mass, and Momentum Transfer, Prentice-Hall, Englewood Cliffs, NJ, 1961.

31. D. C. Groeneveld, S. C. Cheng, and T. Doan, "1986 AECL-UO Critical Heat Flux Lookup Table," Heat Transfer Eng., Vol. 7, pp. 46-62, 1986.

32. J. C. M. Leung, "Transient Critical Heat Flux and Blowdown Heat Transfer Studies," Ph.D. dissertation, Northwestern University, Evanston, II, 1980.

33. R. E. Henry, "A Correlation for the Minimum Film Boiling Temperature," AIChE Symposium Series, Vol. 138, pp. 81-90, 1974.

34. S. C. Cheng, P. W. K. Law, and K. T. Poon, "Measurements of True Quench Temperature of Subcooled Water Under Forced Convection Conditions," Int. J. Heat Mass Transfer, Vol. 20(1), pp. 235-243, 1985.

35. D. C. Groeneveld and J. C. Stewart, "Measurement of Axially Varying Nonequilibrium in Post-Critical-Heat-Flux Boiling in a Vertical Tube," Lehigh University, NUREG/CR-3363, 1983.

36. M. F. Young et al., "The FCI Potential of Oxide and Carbide Fuels: Results of the Prompt Burst Series at Sandia laboratories," Fourth CSNI Specialist Meeting on Fuel-Coolant Interaction in Nuclear Reactor Safety, Bournemouth, UK, 1979.

37. M. F. Young, "The TEXAS Code for Fuel-Coolant Interaction Analysis," in Proc. LMFBR Safety Topical Mtg., 1982.

38. C. C. Chu and M. L. Corradini, "One-Dimensional Transient Fluid Model for Fuel/Coolant Interaction Analysis," Nucl. Sci. Eng., Argonne National Laboratory Vol. 101, pp. 48-71, 1989.

39. M. J. Rightley, D. F. Beck, and M. Berman, NPR/FCI EXO-FITS Experiment Series Report, SAND91-1544, Sandia National Laboratories, Albuquerque, NM, 1991.

40. M. Pilch, "Acceleration Induced Fragmentation of Liquid Drops," Ph.D. dissertation, University of Virginia, Charlottesville, VA, 1981. 
41. G. A. Greene, T. Ginsberg, and N. K. Tutu, "BNL Severe Accident Sequence Experiments and Analysis Program," Proc. Twelfth Water Reactor Safety Research Information Mtg., NUREG/CP-0058, Vol. 3, 1985.

42. L. T. Pong, "A Theoretical Study of the Reactions of Molten $\mathrm{Zr}, \mathrm{Fe}$, and Al with Water," SAND88-7119, Sandia National Laboratories, Albuquerque, NM, 1988.

43. M. F. Young, M. Berman, and L. T. Pong, "Hydrogen Generation During Fuel-Coolant Interactions," Nuclear Sci. Eng., Vol. 98, p. 1, 1988.

44. M. F. Young, "Comparison of Chung, Film Theory, and Steam Starvation Models," Memo to J. P. Rivard, Sandia National Laboratories, Albuquerque, NM, 1982.

45. M. Epstein et al., "Film Boiling on a Reactive Surface," Int. J. Heat Mass Transfer, Vol. 27, p. 1365, 1984.

46. S. Wolfram, Mathematica: A System for Doing Mathematics by Computer, Addison-Wesley, Reading, MA, 1988.

47. E. S. Oran and J. P. Boris, Numerical Simulation of Reactive Flow, Elsevier (1987).

48. S. T. Zaleszak, "Fully Multidimensional Flux-Corrected Transport Algorithms for Fluids," J. Comp. Phys., Vol. 31, pp. 335-362 (1979).

49. A. W. Reed, M. F. Young, and R. C. Schmidt, "Results of the IFCI 6.0 Assessment: Calculations of MAGICO-701, MLXA-6, and KROTOS-26 Experiments," letter report to USNRC, Sandia National Laboratories, Albuquerque, NM, 1995. 


\section{EXTERNAL DISTRUBUTION:}

U.S. Nuclear Regulatory Commission (5)

Division of Reactor System Safety

Office of Nuclear Regulatory Research

ATTN: C. G. Gingrich, T-10K8

S. Basu, T-10K8

Washington, DC 20555-0001

U.S. Department of Energy

Scientific and Technical Information Center

Post Office Box 62

Oak Ridge, TN 37831

Brookhaven National Laboratory

ATTN: R. Bari

Building 130

32 Lewis

Upton, NY 11973

Energy Research, Inc.

ATTN: M. Khatib-Rahbar

Post Office Box 2034

Rockville, MD 20852

Fauske \& Associates, Inc.

ATTN: R. Henry

16W070 West $83^{\text {rd }}$ Street

Burr Ridge, IL 60952

Dr. Thomas S. Kress

102-B Newridge Road

Oak Ridge, TN 37830

Massachusetts Institute of Technology

ATTN: M. Golay

Cambridge, MA 02139

Rennselaer Polytechnic Institute

Department of Nuclear Engineering \&

Engineering Sciences

ATTN: M. Podowski

Tibbits Avenue, NES Building

Troy, NY 12180-3590

University of California

Department of Chemical and

Nuclear Engineering

ATTN: T. Theofanous

Santa Barbara, CA 93106
University of Wisconsin (2)

Department of Nuclear Engineering

ATTN: M. L. Corradini J. Murphy

153 Engineering Research Building 1500 Johnson Drive

Madison, WI 53706

FOREIGN DISTRIBUTION:

AEA Technology

ATTN: B. D. Turland

Winfrith, Dorchester

Dorset DT2 8DH

United Kingdom

Autoridad Regulatoria Nuclear

ATTN: J. Baron

Ayacucho 666

5500 Mendoza

Argentina

CEA

C.E.N.G./S.T.I.

ATTN: G. Berthoud

17 , rue des Martyrs

38054 Grenoble Cedex 9

France

CEC Joint Research Centre, Ispra

ATTN: D. A. Magallon

TP 421

I-21020 Ispra (Varese)

Italy

Commissariat a l'Energie Atomique

ATTN: M. Petit

Boite Postale No. 6

F-92265 Fontenay-aux-Roses Cedex

France

Forschungszentrum Karlsruhe (2)

ATTN: W. Scholtyssek

H. Jacobs

Post Office Box 3640

75 Karlsruhe, D-76021

GERMANY 
Gesellschaft fur Anlagen-und Reaktor (GRS) $\mathrm{mbH}$

ATTN: M. Sonnenkalb

Schertnergasse 1

50667 Cologne

Germany

Health/Safety Exec. Nuclear Instal. Insp.

ATTN: A. Hall

St. Peter's House, Balliol Rd.

Bootle, Merseyside L20 3LZ

United Kingdom

IAEA

Division of Nuclear Reactor Safety

ATTN: M. Jankowski

Wagranerstrasse 5

Post Office Box 100

$\dot{A} / 1400$ Vienna

AUSTRIA

Institute for Electric Power Research Division of Nuclear \& Power Engineering ATTN: Z. Techy

P.O. Box 80

H-1251 Budapest

Hungary

Institute of Nuclear Energy Research

Nuclear Engineering Division

ATTN: S. J. Wang

1000 Wenhua Rd. Chiaan Village

P.O. Box 3

Lungtan

Taiwan 325, Republic of China

Institut Jozef Stefan

Reactor Engineering Dept.

ATTN: B. Mavko

P.O. Box 100

61111 Ljubljana

Slovenia

Japan Atomic Energy Research Institute Department of Fuel Safety Research

ATTN: K. Hashimoto

Tokai-mura, Naka-gun

Ibaraki-ken, 319-11

Japan
Korea Atomic Energy Research Institute

ATTN: Hee-Dong Kim

150 Dukjin-dong, Yusong-ku

Taejon 305-353

KOREA

Korea Institute of Nuclear Safety

Safety Review and Assess. Div.

ATTN: J. I. Lee

P.O. Box 114, Yusong

Taejon, 305-600

Korea

Netherlands Energy Research Foundation, ECN

Unit Nuclear Energy

Safety \& Reliability Engineering

ATTN: R. Jansma

P.O. Box 1

NL-1755 ZG Petten

The Netherlands

Nuclear Fission Energy Sector

ENEA

ATTN: M. Pezzilli

C.R. Casaccia, Via Anguillarese, 301

00060 S. Maria de Galeria (Rome)

Italy

Nuclear Power Engineering Corp.

Advanced Simulation Systems Dept.

ATTN: M. Naitoh

Fujita Kanko Toranomon Bldg. 7F, 17-1

3-Chome Toranomon, Minato-Ku

Tokyo 105, Japan

Nuclear Research Institute Rez plc

ATTN: J. Duspiva

$25068 \mathrm{Rez}$

Czech Republic

Nuclear Regulatory Council of Spain

ATTN: A. Alonso

Consejo de Seguridad Nuclear

Justo Dorado, II

28040 Madrid

Spain

Royal Institute of Technology

Nuclear Power Safety

ATTN: B. R. Sehgal

S-100 44 Stockholm

SWEDEN 
Russian Academy of Sciences

Nuclear Safety Institute

ATTN: V.F. Strizhov

52, B. Tulskaya

113191 Moscow

RUSSIA

South Africa Council for Nuclear Safety

Quantitative Risk Assess. \& Compl. Dept.

ATTN: T. Hill

P.O. Box 7106

Hennopsmeer 0046

Republic of South Africa

Swedish Nuclear Power Inspectorate

ATTN: W. Frid

Post Office Box 27106

S-102 52 Stockholm

SWEDEN

TracteBel

Operation \& Accident Analysis Section

ATTN: M. Auglaire

Avenue Ariane 7

B-1200 Brussels

Belgium

University of Sydney

Dept. of Chemical Engineering

ATTN: D.F. Fletcher

NSW 2006, Australia

VTT Energy

ATTN: R. Sairanen

Leader of Accident Management Group

Tekniikantie 4 C, Espoo-Otaniemi

P.O. Box 1604, FIN-02044 VTT

Finland

\section{INTERNAL DISTRIBUTION:}

MS0619 Review \& Approval Desk, 00111 (1)

For DOE/OSTI

MS0736 D. A. Powers (6400)

MS0739 K. D. Bergeron (6421) (5)

MS0739 M. F. Young (6421) (5)

MS0742 J. R. Guth (6414)

MS0899 Technical Library, 4916 (2)

MS1139 M. M. Pilch (6423)

MS1139 K. O. Reil (6423)

MS9018 Central Technical Files (8940-2) 